\title{
Article \\ Dimensional Stability of 3D Printed Objects Made from Plastic Waste Using FDM: Potential Construction Applications
}

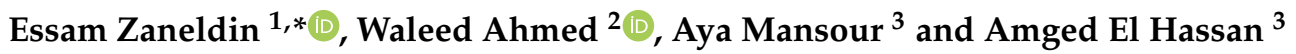 \\ 1 Department of Civil and Environmental Engineering, United Arab Emirates University, \\ Al-Ain P.O. Box 15551, United Arab Emirates \\ 2 Engineering Requirements Unit, College of Engineering, United Arab Emirates University, \\ Al-Ain P.O. Box 15551, United Arab Emirates; w.ahmed@uaeu.ac.ae \\ 3 Mechanical Engineering Department, United Arab Emirates University, \\ Al-Ain P.O. Box 15551, United Arab Emirates; 201540185@uaeu.ac.ae (A.M.); 201450104@uaeu.ac.ae (A.E.H.) \\ * Correspondence: essamz@uaeu.ac.ae
}

Citation: Zaneldin, E.; Ahmed, W.; Mansour, A.; Hassan, A.E. Dimensional Stability of 3D Printed Objects Made from Plastic Waste Using FDM: Potential Construction Applications. Buildings 2021, 11, 516. https://doi.org/10.3390/ buildings11110516

Academic Editors: Alexandros

A. Lavdas, Nikos A. Salingaros, Michael W. Mehaffy, Ann Sussman and Francesco Colangelo

Received: 21 August 2021

Accepted: 26 October 2021

Published: 3 November 2021

Publisher's Note: MDPI stays neutral with regard to jurisdictional claims in published maps and institutional affiliations.

Copyright: (C) 2021 by the authors Licensee MDPI, Basel, Switzerland. This article is an open access article distributed under the terms and conditions of the Creative Commons Attribution (CC BY) license (https:// creativecommons.org/licenses/by/ $4.0 /)$
Abstract: Construction projects are often challenged by tight budgets and limited time and resources. Contractors are, therefore, looking for ways to become competitive by improving efficiency and using cost-effective materials. Using three-dimensional (3D) printing for shaping materials to produce cost-effective construction elements is becoming a feasible option to make contractors more competitive locally and globally. The process capabilities for 3D printers and related devices have been tightened in recent years with the booming of 3D printing industries and applications. Contractors are attempting to improve production skills to satisfy firm specifications and standards, while attempting to have costs within competitive ranges. The aim of this research is to investigate and test the production process capability $(\mathrm{Cp})$ of 3D printers using fused deposition modeling (FDM) to manufacture 3D printed parts made from plastic waste for use in the construction of buildings with different infill structures and internal designs to reduce cost. This was accomplished by calculating the actual requirement capabilities of the $3 \mathrm{D}$ printers under consideration. The production capabilities and requirements of FDM printers are first examined to develop instructions and assumptions to assist in deciphering the characteristics of the 3D printers that will be used. Possible applications in construction are then presented. As an essential outcome of this study, it was noticed that the 3D printed parts made from plastic waste using FDM printers are less expensive than using traditional lightweight non-load bearing concrete hollow masonry blocks, hourdi slab hollow bocks, and concrete face bricks.

Keywords: 3D printing; construction applications; dimension limits; process capabilities; reliability

\section{Introduction}

Three-dimensional printing has recently emerged as a robust sector that is rapidly evolving to revolutionize industrial processes. In general, fused filament fabrication (FFF), also known as FDM, is one of the most traditional, affordable, and easy to use 3D printing technology. Although there are many alternative meanings for 3D printing technology, according to ISO/ASTM 52900:2015, 3D printing is defined as: "the fabrication of objects through the deposition of a material using a print head, nozzle, or another printer technology", while additive manufacturing (AM) is "the process of joining materials to make parts from 3D model data, usually layer upon layer" [1,2]. Three-dimensional printing is currently used in several industries, including mechanical, electrical, biomedical, and aerospace, to boost design fabricating, reduce lead times, and minimize the tooling costs of new parts to be produced. Three-dimensional printing is distinct, when compared with techniques of traditional machines, such as grinding, milling, and spinning, which were used to build objects several decades earlier. However, these machines have not been used as much in recent years, due to certain shortcomings and restrictions, including the 
high cost of manufacturing processes. Despite these shortcomings and restrictions, the principle of 3D printing is considered as part of the manufacturing processes, since it is considered a significant field of prototyping that enables the creation of 3D digital models. Additive manufacturing is described as laying down a particular material layer-by-layer to form the object according to the specifications. The horizontal cross-section of the substance is made up of specific layers that are stacked one on top of the other. The consistency of an item printed using a 3D printer is determined by the type of material used, the printing process, the printer's speed, the kind of 3D printer, and the size of the printed parts. In general, due to its significant contribution to the manufacturing industry and construction applications, 3D printing has benefited the world in a variety of ways [3,4]. Other fields have also benefited from this breakthrough, such as prototyping, simulations, and failure mechanisms $[5,6]$. The construction and aerospace industries are two sectors that have benefited from 3D printing technology, due to the extensive and varied applications that $3 \mathrm{D}$ printing can offer for both industries [7]. In addition, 3D printing technology has begun to be adopted at various schools and universities, as well [8-10].

In essence, there is a substantial increase in the use of plastics from the additive manufacturing sector, since several plastic products can also be utilized in AM processes, providing great flexibility in creating complex designs. Furthermore, the commercial $3 \mathrm{D}$ printing filament material market volume is rapidly growing, and the most popular filament materials are polylactic acid (PLA) and acrylonitrile-butadiene-styrene (ABS), holding about $47 \%$ and $29 \%$ of the market share, respectively [11]. There are a variety of tools that 3D printers use to print objects, with the operation beginning with a 3D CAD model, converted to a format that the 3D printer can understand, and ending with the production of an actual physical component [12]. In specific methods, the substance used to create the object layers must be liquefied or weakened. In some cases, a high-powered ultraviolet (UV) laser is used to cure photo-reactive resin and print the product; while, in other cases, a low-powered UV laser is used [13]. There are widely used 3D printing methods [14-18], such as stereolithography (SLA), digital light processing (DLP), electronic beam melting (EBM), laminated object manufacturing (LOM), fused deposition modelling (FDM), and selective laser sintering (SLS).

\subsection{Potential Applications of 3D Printing}

Design prototypes: models for testing and optimizing design and packaging include a three-dimensional printing concept model, practical porotypes, and presentation models $[19,20]$.

Education: bring interactive ideas to life to engage students, transforming their concepts into tangible 3D color models they can keep in their hands [21,22].

Healthcare: reduce running time by rapidly creating 3D models; patients' results will be improved, due to the enhancement of patient care [23,24].

Architecture: create design models, smooth, accurate architectural models in various materials, including rigid photopolymers, in a short amount of time [18].

Construction: create reliable, cost-effective, non-structural, and non-load bearing construction building components, such as lightweight masonry blocks, light weight concrete face bricks, hourdi slab blocks, tiles, partition walls, and fillers $[25,26]$.

\subsection{Types of Infill}

A 3D parts' filling has many functions at once. Internal form, on the one hand, occupies the object's void. On the other hand, the weight, as well as it, may be adjusted. The pattern and filament are used to determine the weight, since not all filaments are the same weight. Another advantage of infill is that it allows 3D printers to print horizontal flat edges easily and effectively along with void. Three-dimensional printers would be unstable and lack structure if this filling was not present. It is worth noting that infill strengthens structures and prevents cracking too quickly. Infills are essential aspects of three-dimensional printing that can be used in a variety of ways. Optimize the infill 
by choosing from a variety of designs, styles, densities, and alignments $[27,28]$. While, theoretically, there are an infinite number of infill configurations, only three standard infills are commonly used in 3D printing: solid, light, and ultra-light infill. The three types of infill configurations were demonstrated by Yap et al. [18]. The three different infill patterns have different densities that depend on the profile of the pattern.

There is a wide range of factors, but the common parameters among all technologies are layer thickness, build orientation, infill pattern, and temperature [28]. Other factors, such as humidity, material properties, and environment, also have effects on the printing process. Unfortunately, controlling these factors is complex and they may change the mechanical properties of final products. Besides, there are other limitations, such as staircase defects in AM, that are highly effective on surface texture [29]. Many technologies are involved in AM and have various features, but FDM or material extrusion is one of the most common and widely used technologies [30].

\subsection{Standard Deviation and Tolerance}

The standard deviation $(\sigma)$ is a metric that calculates the variation of a data set concerning its mean, and the square root of the variance is used to measure it. A low standard deviation means that data is clustered around the mean, while a high standard deviation indicates that data is more dispersed [31].

The tolerance, on the other hand, is a dimensional precision. Machining tolerances refer to the amount of variation in a part's dimension, created by the production process. Since no computer can keep dimensions properly, dimensional tolerances are added to components as constraints of the required structure, with adequate levels of dispersion set. The critical issue is what tolerance could be removed without affecting individual parameters or device outcomes. Once a component has been made with out-of-tolerance dimensions, it becomes unusable because the key features of this component were not designed with that in mind [32].

\subsection{Process Capability and Performance Indicators}

A method is a set of interconnected processes, steps that absorb data and translate inputs to outputs. Any stage results in the achievement of a desired goal or outcome. Each procedure has a limited degree of variance. It is not possible to element system variability; however, we can control and regulate it by using process controllers, taking samples, and using safe and well-maintained tools. System variability may have less impact on output efficiency. The method is capable of reliably yielding a good result. We would be able to retain process capability. Process capability compares the output of an in-control process to the specification limits by using capability indices. The comparison is made by forming the ratio of the spread between the process specifications to the spread of the process values, as measured by six process standard deviation units. Any quality control process needs to quantify the machine capability in one continuous production run and the manufacturing process capability in series production $[33,34]$. Measurement process capability provides the evidence for conformity or nonconformity with specification, according to ISO 14253:2017 [35,36].

Process capability $(\mathrm{Cp})$ is a statistical indicator of a process's ability to manufacture components under defined limitations reliably. Based on the process state and the way of determining the values of the standard deviation value, the $\mathrm{Cp}$, process capability index (Cpk), preliminary process capability (Pp), and preliminary process capability Index (Ppk) are measured to decide how the system works. The $\mathrm{Cp}$ and $\mathrm{Cpk}$ calculations use sample variance, or deviation mean in rational subgroups, while the Pp and Ppk are calculated using standard deviation, based on the data analyzed (whole population). In statistical control, the indices $\mathrm{Cp}$ and $\mathrm{Cpk}$ measure fundamental well-built-up procedures. The $\mathrm{Pp}$ and Ppk indices assess a novel or statistical system [37].

Indicators of process capability $\mathrm{Cp}$ and Cpk assess the process's success, regarding the tolerance range and goal value, which serve as specification constraints. $\mathrm{Cp}$ indicates 
whether your device can produce parts within limits, while Cpk indicates whether the machine measurements are within the limited tolerance. Engineers should consider the capabilities of the process when designing components. The $\mathrm{Cp}$ index is an essential metric for determining a mechanism's capability. Customers define process goals for those demand levels, which are then used to determine capability. In essence, the applicable limits that customers have already considered are the upper specification limit (USL) and lower specification limit (LSL). The general equation to calculate the $\mathrm{Cp}$, considering the USL, the LSL, and the standard deviation $(\sigma)$, is as follows [38]:

$$
\mathrm{Cp}=\frac{\mathrm{USL}-\mathrm{LSL}}{6 \sigma}
$$

In general, specification limit is set by the customer or the designer of engineering components and usually referred to the voice of the customer because they represent the values that the designer or customer requires; they are the limits on the product characteristics that define where the product will or will not work, and if the products falls outside theses specifications, the product will be rejected [33,34]. Basically, there are two types of specification limits, the upper specification limit (USL) and the lower specification limit (LSL). This specification limit should be considered at the point or level where the losses, due to variation, will result in the benefit of the product. This limit often, but not always, has been to symmetric, which depends, again, on the customer or the designer requirements. So, if the part falls between the USL and LSL, the part will meet the customer or the designer's expectations, but if it falls outside this range, it will be rejected. Specification limits are used to determine the process capability and the sigma values $[37,38]$. So, to specify the dimensional tolerance of the measured parts, ASME Y14.5 (dimensioning and tolerancing) or ISO 1101 (geometrical product specifications) could be used to identify the part tolerances that would be reflected on the USL and LSL. Basically, in the present investigation, the tested parts' cross-sectional area has a dimension $20 \mathrm{~mm} \times 20 \mathrm{~mm}$ that fall within linear dimension range from $6 \mathrm{~mm}$ to $30 \mathrm{~mm}$, where the tolerance class is considered as fine $( \pm 0.1)$, medium $( \pm 0.2)$, coarse $( \pm 0.5)$, and very coarse $( \pm 1)$. The medium tolerance class $( \pm 0.2 \mathrm{~mm})$ has been chosen and is $1 \%$ of the tested part's symmetric dimension (i.e., $20 \mathrm{~mm}$ ). Accordingly, in this study, the upper specification limit is considered USL $=20.2 \mathrm{~mm}$, and the lower specification limit is considered LSL $=19.8 \mathrm{~mm}$.

Many production firms need a processing capacity (Cp) of 1.33 or higher. The Cpk index from the processing center evaluates whether the process is close to the limitation of the design when normal process variance is considered. The higher the Cpk value, the closer the data mean is to the target value. The limits of specification, standard deviation or sigma, and mean value are used to measure Cpk. Cpk should be in the range of 1 to 3 , and the method must be changed if the value is less than one. The Cpk formula is represented by $[38,39]$ :

$$
\mathrm{Cpk}=\min (\mathrm{CpU}, \mathrm{CpL})
$$

where,

CpU: estimates process capability for specifications that consist of an upper limit only (assumes the process output as normally distributed).

CpL: estimates process capability for specifications that consist of a lower limit only (assumes the process output as normally distributed).

Process capability index (Cpk) is a statistical tool used to measure the ability of a process to produce output within customer's specification limits. In simple terms, it measures a producer's capability to produce a product within customer's tolerance range. Cpk is used to estimate how close we are to a given target and how consistent we are to the average performance. Cpk gives the best-case scenario for the existing process. It can also estimate future process performance, assuming the performance is consistent over time.

The following three specific data assumptions are needed for accurate process capability studies [39]: 
1. There are no unique causes of variance in the method, and statistical regulation is in place. It is essential to identify and address these individual problems.

2. The results match a normal distribution, with a bell-shaped curve and a numerical approximation of more minor than, or greater than, 3 Sigma. In certain situations, the data does not conform to the typical distribution assumption.

3. The survey data is reflected in the population. Data from a big production run can be taken at random. In most cases, at least 25 to 50 sample measurements are ideally needed.

To survive in this competitive market, manufacturing companies should minimize waste to have a high-quality product. Therefore, process capability should be measured, and various types of waste should be produced during the process to reduce cost and optimize benefits. Therefore, reusing polymeric waste materials gives a possibility for a second life and enables effective waste utilization to obtain consumable products. Printable filaments can be made from various thermoplastic recycled materials as an alternative to the current approach of central selective collection of plastics [40]. The possibility of recycling basic thermoplastic materials impacts processing, which will be reflected in their physical, chemical, and mechanical properties. The advantage is to offer commercial filaments, produced from recycled materials, that promote the production of filaments to 3D printing from plastic waste [41]. Recycling facilities have developed several processes to recover and reuse plastics. The most common practice in the industry is to extrude melted plastic into small pellets (often referred to as mechanical or traditional recycling). Mechanical recycling is most efficient when working with a single type of material. The recycled pellets, which are then sold to manufacturers as raw materials, serve as a cost-effective and environmental alternative to virgin plastics. The pellet form allows the plastic to be easily distributed and used to produce new parts [42]. Traditionally recycled pellets suffer from lowered and inconsistent mechanical properties and, therefore, recycled resin is often downcycled into cheaper products [43].

Measuring process capability is not only estimating the $C p$ and $C p k$ values. Process capability is only one instrument in the statistical process control (SPC) implementation that requires data collection and interpretation to understand the predictive output of the operation and pinpoint the sources of uncertainty. Focusing on the capacity of the method yields essential information. System capability management allows for evaluating and adjusting the production process required to ensure that goods fulfill the design and consumer specifications. If this information is appropriately used, it will help to eliminate waste, improve production efficiency and consistency, and lower manufacturing and lowquality costs [44]. In addition, this will help to determine the stability of the dimensions of the 3D printed components, while increasing the height.

The impact of process variables, such as layer thickness and raster angle, on the linear and radial dimensional accuracy of poly latic acid components manufactured by fused deposition modeling was investigated. The measurements of the manufactured components were smaller than the CAD model because of the shrinking that takes place during the cooling of the material after depositing layers. Because of the chopping and squaring of corners, the dimensional inaccuracy of the radial dimension (RD) was more significant than that of the linear dimension (LD). For both LD and RD, the international tolerance grade (IT-grade) was assessed as IT-grade measures any machine's dimensional precision. The linear axis has a lower IT-grade than the radial dimension, according to the findings. With all of the experiments, IT-grade remained constant across a particular range [45].

In a different study, mathematical analysis was used to analyze 3D printed pieces with honeycomb patterns through fused deposition modeling. The honeycomb pattern is used to produce inside samples, since it has a feature to resist applied loads. Cutting a 3D sample into slices and changing the thickness of the layer, infill portion, and temperature of the extruder was all done in 3D. The performance responses of build time, maximum failure load, elongation at break, and component weight were chosen and evaluated using 
the response surface tool. The layer thickness was defined as the most crucial regulated parameter for all interactions, based on the analysis of variance. Elongation at break and, therefore, extreme cracking and lesson build time, is significantly affected by the infill portion and extruder temperature [46,47]. It is noticed that, when comparing the mechanical properties of printed pieces, the dimensional precision of the internal structure has received little attention in the literature of recent years. As a result, research was conducted to calculate and compare the inner structure's dimension precision using various scanning techniques. The findings revealed that the printed internal pattern in the scanning direction is more reliable, in terms of dimensional accuracy, than the vertical printing process in the scanning direction. According to the finite element analysis (FEA) data, the distribution of temperature over the scanning path is uniform in the vertical direction. As a result, it is expected that dimensional variation will occur during printing [48].

\subsection{Dimensional Accuracy}

The capability of the FDM process to keep a high level of precision in the dimensional stability of the manufactured components is significant and crucial to the overall market acceptance of this method, particularly in investment casting pattern applications [49]. The dimensional tolerances of the pattern must not exceed half of the casting's tolerance in applications of investment casting patterns. Therefore, it is critical to achieving very low dimension tolerances between the manufactured and CAD models. The dimensional accuracy of components manufactured by FDM is affected by many conflicting parameters, as shown in Figure 1.

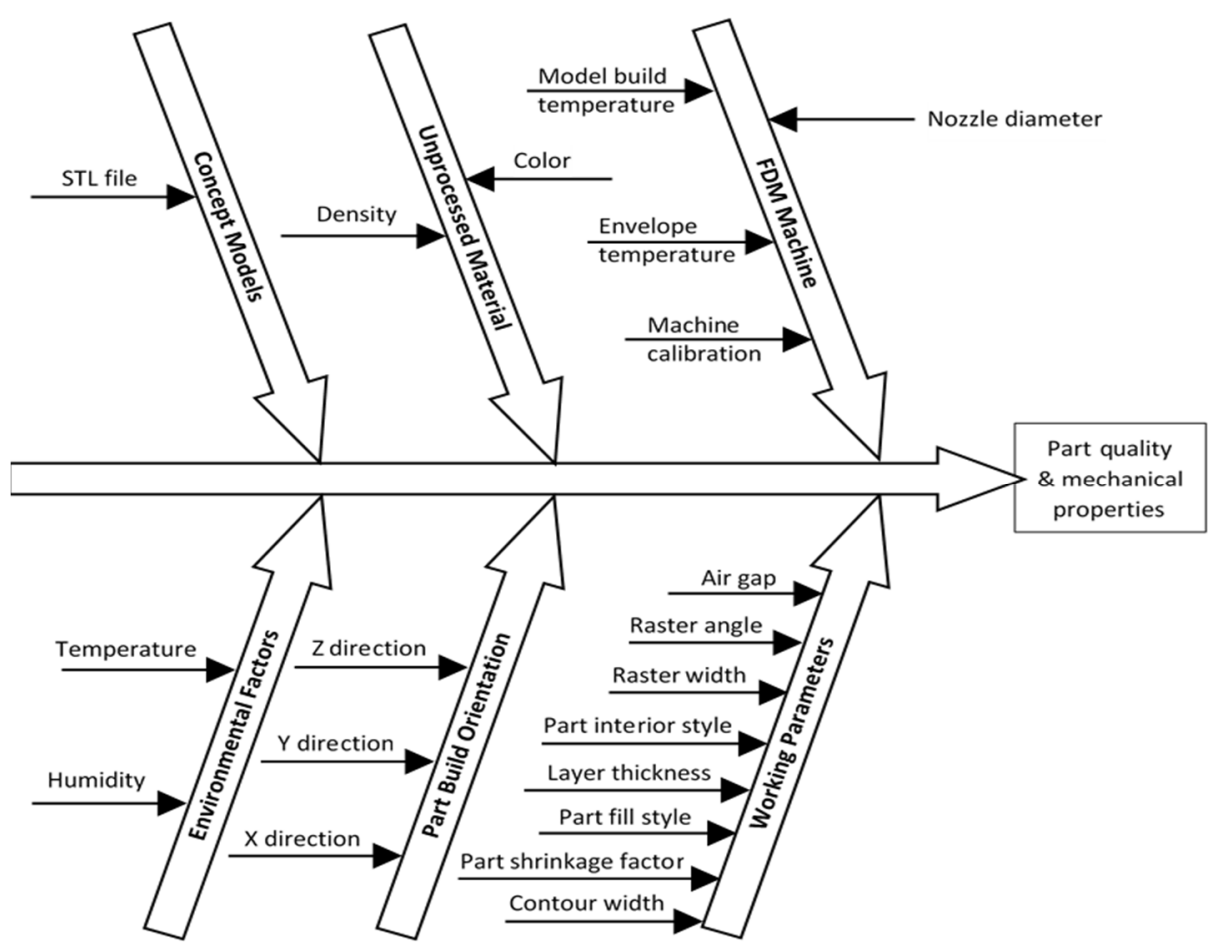

Figure 1. FDM method parameter cause and effect diagram.

Using the SLA, PolyJet, and SLS, the dimensional accuracy of components was affected by a few primary parameters. Previous research has shown that the FDM process produces fabricated parts with lower dimensional accuracy than other AM processes [50] because there is a range of conflicting process parameters that affects dimensional accuracy, either individually or in combination with different parameters [51]. Obtaining a high degree of dimensional precision in this method is a significant quality characteristic in many industrial applications, such as electronics, medical devices, and aerospace. Preserving dimensional accuracy, with a very low tolerance in those applications, will ensure 
dimensional stability and repeatability of the processed component. To obtain accurate built components, the development of mathematical models to optimize the settings and comprehend the relation between the parameters of a process and dimension accuracy are essential [49]. The following parameters would be used to help measure the accuracy of 3D printed parts:

i Dimensional accuracy: quantitative values reflect the desired accuracy of parts, which machine manufacturers and material suppliers give. All tolerances are calculated based on well-designed elements operating on well-calibrated machines.

ii Warping or shrinkage: the probability of a component warping or shrinking during the printing process. This is highly dependent on the design, although specific techniques are required to manufacture parts that are predisposed to warping or shrinkage.

iii Support requirements: the amount of support used determines how precisely a surface or element is printed in certain 3D printing technologies. The disadvantage is that it reduces the part's surface finish [52].

\subsection{Hypothesis}

Process capability analysis is a scientific and systematic procedure that involves the measurement and assessment of natural variations in quality characteristics (attributes and dimensional) of a process. In statistical process control, the variations in the performance measures are due to chance causes only [53]. Process capability analysis is applied to design a process control system or for commissioning machines/equipment to determine their deliverance, in terms of output, as per specifications [54]. The pattern of variations of a process is detailed by the probability distribution; this hypothesized distribution is then compared with the corresponding specifications to assess its adequacy. Process capability indices attempt to summarize the process performance and, hence, are a function of the process distribution and the corresponding specifications [55]. The process capability analysis is performed to determine the power of ability of a process or operation (hence, is responsible for the quality of any product) [56]. The purpose is to analyze, estimate, monitor, and absorb the variance in manufacturing processes [57]. Process capability indices are the tools that are employed to assess the quality of a process [58]. The following are the hypothesis of this study:

Hypothesis 1. Propose to investigate the dimensional accuracy of commercial desktop 3D printers using PLA of a square cross-sectional area at different infill patterns and incremental heights. The expected result from this study is to understand and assess the impact of the infill pattern and height of $3 D$ printed objects on the dimensional accuracy.

Hypothesis 2. Propose that the $3 D$ printing conditions are consistent, such as material used, printing speed and temperature, extrusion nozzle size, and room temperature, while printing throughout the investigation.

Hypothesis 3. Propose that there is neither vibration on the $3 D$ printed objects while printing, which would affect the dimensional accuracy, nor vibration of the printing bed. Besides, it is, assumed, that the 3D printed objects are firmly bonded with the printing bed and that the infill pattern will have no impact on the stability of the adhesion performance.

\section{Methodology}

In this research, the Ultimaker 2 extended machine was used to print different dimensions and infill structures. The Ultimaker extended machine specifications are given in Table 1. 
Table 1. Ultimaker 2 extended machine specifications [59].

\begin{tabular}{cc}
\hline Software & Ultimaker Cura [60] \\
\hline Technology & Fused filament fabrication (FFF) \\
Nozzle temperature & $180{ }^{\circ} \mathrm{C}$ \\
XYZ resolution & $12.5 \mathrm{micron}$ \\
Print head travel speed & $300 \mathrm{~mm} / \mathrm{s}$ \\
Max build size & $150 \mathrm{~mm} \times 150 \mathrm{~mm} \times 150 \mathrm{~mm}$ \\
Filament diameter & $2.85 \mathrm{~mm}$ \\
Material & PLA [61] \\
Nozzle diameter & $0.4 \mathrm{~mm}$ \\
Print head & $0.15 \mathrm{~mm}$ \\
Layer height & $1 \mathrm{~mm}$ \\
Wall thickness & $1 \mathrm{~mm}$ \\
Top/bottom thickness & $20 \%$ \\
Infill density &
\end{tabular}

In general, the eruption of 3D printing technology has led to a massive new waste source of plastics, especially the polylactic acid (PLA), which is associated with the fused deposition modeling (FDM) process [2]. The usage of polymers in three-dimensional printing technology has grown exponentially, which has increased the amount of waste produced during this process. Recycling polymeric waste is considered to be more practical and economical than other waste disposal techniques. The vision of the plastic economy requires innovative methods to develop sustainable solutions for manufacturing products that have high durability, prolonged shelf-life, and retain quality after recycling [62]. In this study, all parts were printed with PLA material and were rectangular in shape. There were five sets of parts, each set had four rows, and each row had three samples. All rows had base dimensions of $20 \mathrm{~mm} \times 20 \mathrm{~mm}$, but the height changed across the rows. For example, the first row was 20 , the second was 40 , the third was 80 , and the fourth row was $150 \mathrm{~mm}$ high. Triangular, concentric, rectilinear, gyroid, and honeycomb filling patterns were among the infill patterns available on the Ultimaker 2 printing machine. The various infill pattern structures were [63]: rectilinear, grid, triangles, stars, cubic, line, concentric, honeycomb, 3D honeycomb, gyroid, hilbert curve, archimedean chords, and octagram spiral.

Polylactic acid (PLA) is one of the most popular filament materials among the thermoplastics, which are currently available for 3D printing. The costs of commercial filaments are up to 200 times higher than those of raw plastics [64], though their thermo-mechanical recycling would significantly contribute to the reduction of 3D printing cost. Simplicity and low costs have contributed to the fact that it is primarily used in prototyping and small-scale productions. In recent years, the use of $3 \mathrm{D}$ printing has become more prevalent in various industrial sectors, with the aerospace, military, automotive, medical, and construction industries increasingly taking advantage of it [65]. The reuse of unsuccessful prints, used parts, disposable prototypes, and waste materials was not necessarily originally used for 3D printing, as a source of materials for filament production is beneficial both economically and for the environment. This reduces material costs, $\mathrm{CO}_{2}$ emission, and energy consumption [66]. Recycling is the most effective way to reduce printing costs. However, research on the recycling of 3D printing waste is limited. Usually, 3D printing waste, such as PLA, is mainly treated by physical recycling methods, such as shredding and reprocessing after melting or high-temperature degradation. However, these methods are challenging for achieving efficient and green recycling.

Due to the high scrap rate of 3D printing, the reuse of waste PLA decreases the costs and reduces the waste of resources [67]. In general, a shredder, dryer, and extruder with a puller are necessary to produce the $3 \mathrm{D}$ printing filament [68]. These machines are used to produce polymeric filaments that can be used in 3D printers and, consequently, close the loop for plastic. PLA can be collected from different resources to have enough waste for the recycling process. It is necessary to classify plastics by color. After the waste is 
shredded (to get small granules) and dried for three hours (to eliminate moisture), the extruder with heaters is used to melt the granules and push them through a nozzle head to achieve filaments of different diameters, which depends on the nozzle size used in the extruder. Usually, a puller is used to help us coil the filament in the spools. Using the raft to make a stable model with a minimal footprint provides a solid basis for constructing the pieces' upper layers. The thickness of the raft was $1.12 \mathrm{~mm}$. Figure 2 shows the printed parts. The recommended settings are as follows:

- $\quad$ Standard prints: triangles;

- Functional prints: the gyroid;

- Flexible prints: concentric.
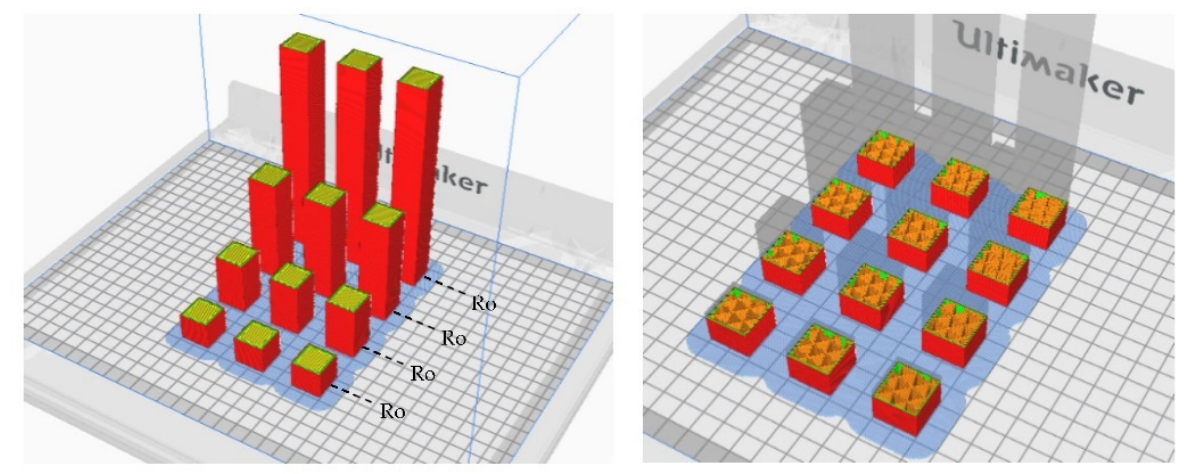

Figure 2. Cura 3D printed set simulation and the triangular pattern of the printed set.

In this study, five patterns were considered, which were: triangle, rectilinear, gyroid, honeycomb, and concentric, as shown in Figure 3:

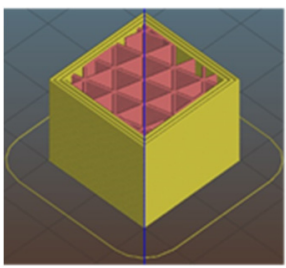

Triangle

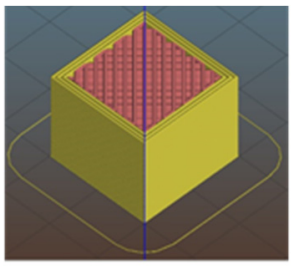

Rectilinear

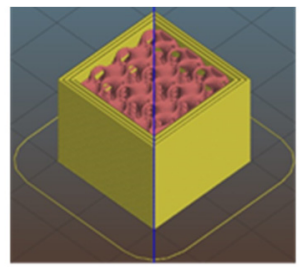

Gyroid

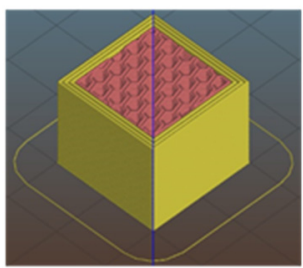

Honey-comb

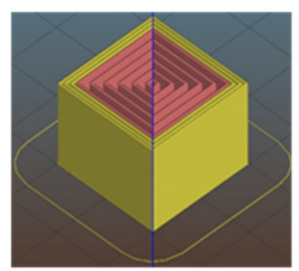

Concentric

Figure 3. The five patterns used in the current investigation.

The mid-height of the 3D printed specimens that have been produced are illustrated in Figure 4.

It is worth mentioning that in this study, the terms top, middle, and bottom, in fact, refer to the 3D printed specimen that has been removed from the printer and is no longer on the printing bed. Therefore, the measurements of the dimensions that have been taken are measured on the part directly, not when the pieces are on the printing bed. Besides, a raft is usually used below the printed parts (i.e., over the printing bed) to help with warping and bed adhesion; it can be used to assist in stabilizing printed models with small footprints, as well as to create a strong foundation, on which to build the upper layers of the printed parts. Most of the slicing software optimizes the raft layer to ensure easy 
separation and a high-quality surface finish on the bottom of the printed pieces. Therefore, once the print is complete, the raft layer is easily peeled away from the printed object and can be discarded.

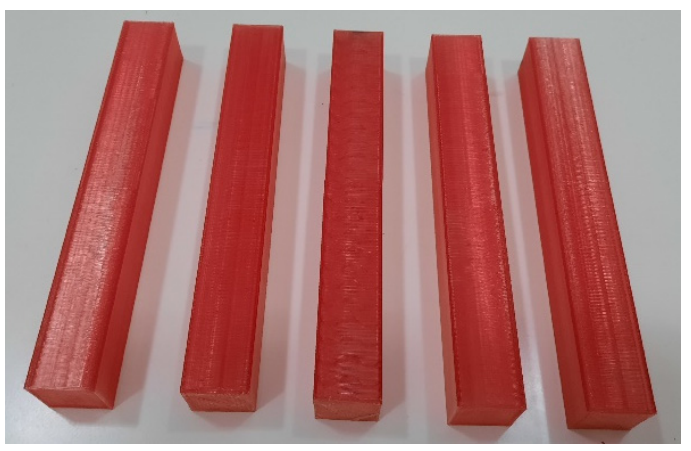

Figure 4. The five specimens of the different infill patterns.

New intelligent technologies took the measurements of the printed parts. An advanced vernier caliper (Mitutoyo caliper to USB package, 6", resolution $0.01 \mathrm{~mm}$ ), connected to the monitor, was used to get the accurate measurements (stored in an Excel sheet). This advanced caliper measuring device provides all of the items required to measure parts accurately and then sends the measured data to a PC through a USB port. This innovative method assisted in saving time and reducing human errors. To minimize errors and evaluate the 3D printer performance at various stages, the $\mathrm{X}, \mathrm{Y}$, and $\mathrm{Z}$ dimensions were measured three times at the bottom, middle, and top levels, as shown in Figure 5.
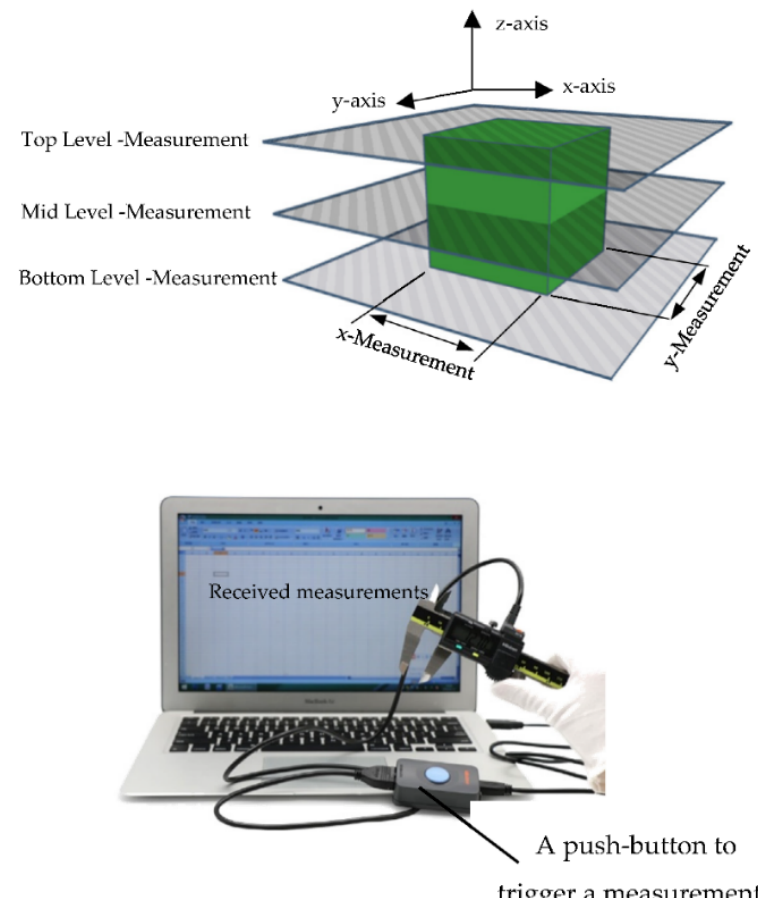

Figure 5. Three-level of measurement locations of $x, y$, and $z$ dimensions and the measuring caliper.

Figure 6 shows the components of the 3D printing process. The 3D printer used in this study was composed of an FDM nozzle, filament extrusion, a cantilever beam, a raft layer, and a printing bed, as illustrated in Figure 6. 


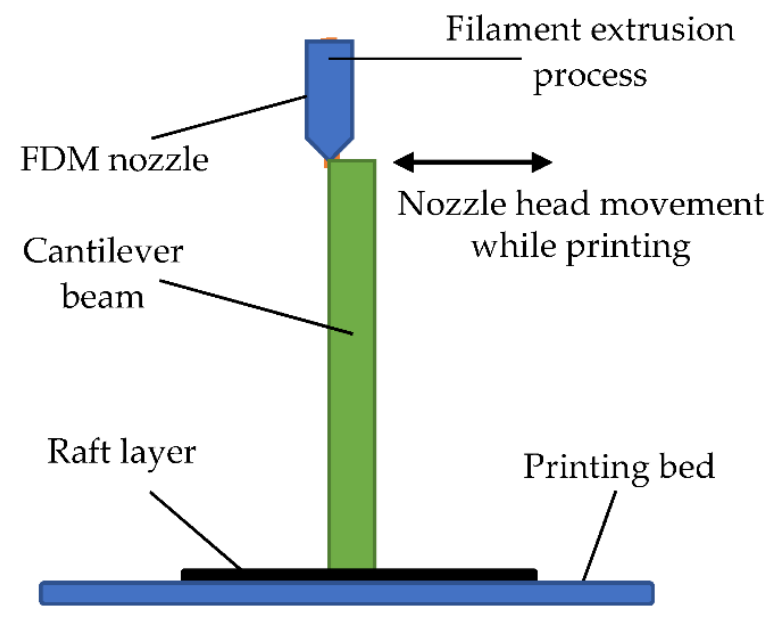

Figure 6. A sketch showing the components of the 3D printing process.

\section{Results}

After recording the measured dimensions, the process capability of 3D printing machines (1) and (2) was calculated using Equations (1) and (2). For all printed parts, calculations were performed repeatedly for the various sets, rows, and levels. Since histograms depict the distribution or dispersion of measured results, they were used to display the distribution of the measured dimensions and verify whether they were within the specification limits. A box-and-whisker plot was constructed to explain the spread of measurement data across three quartiles for the middle and top levels. Tables for each set show the effects of the statistical parameters measured on the method capabilities investigated in this study. There is a clear difference in the process capability of the 3D printed parts using different infill structures in the analysis, as shown in the data. Furthermore, the processing capacity varies with the height of the printed parts, which should be considered when designing 3D printed components. The following subsections present the statistical results, process capability, and performance indicators for the triangular, rectilinear, gyroid, honeycomb, and concentric patterns.

\subsection{Set 1: Triangular Pattern}

Table 2 illustrates the triangular pattern's printed samples after taking measurements across three different levels and four heights. The table shows the values for the dimensions mean and standard deviations and the $C p$ and $C p k$ values. The dimension mean values were almost the same along all rows for the bottom level (Table 2a). The dimension standard deviation, $\mathrm{Cp}$, and $\mathrm{Cpk}$ in the first row were $0.068,0.98$, and -0.11 , respectively. Standard deviation increased dramatically by $71 \%$ in the second row, to reach a peak, before dropping by $21 \%$ to its lowest value in the third row and rising again to 0.106 . It was noticed that the Cpk value in row 1 is -0.11 and grew to its peak in row 3 to reach -0.04 (an increase of $63 \%$ ), before dropping to -0.1 in row 4 . On the other hand, the Cp fluctuated and reached its peak (1.25) in row 3 (an increase of around 27\%), which represented the most capable process, and decreased to 0.63 in the fourth row. The mean value was the same for the first two rows and was reduced by $0.074 \%$ in row 3, before increasing to 20.23 in row 4 . Regarding the middle level (Table $2 \mathrm{~b}$ ), the standard deviation increased in row 2 by around $74 \%$, reflecting the discrepancy in the dimensions at that level of the printing. In comparison, the $\mathrm{Cp}$ decreased by approximately $41 \%$. Following the same trend as the bottom level, with the standard deviation dropped again in row 3 , before increasing to a value of 0.1 in row 4 . The Cpk dropped in row 3 to its minimum $(-0.27)$, before it peaked in row 4 to a value of -0.15 (an increase of more than $44 \%$ from row 3 ). The Cp dropped in row 2 , then increased to a maximum value of 1.25 , then dropped again to a value of 0.63 . For the top-level (Table 2c), the standard deviation of the dimensions and the $\mathrm{Cp}$ values followed the same trend of the middle level, while the Cpk value raised in row 2 by $47 \%$, 
then dropped in row 3 to -0.22 , before it increases to -0.11 (an increase of $63 \%$ from row 1 ). This is attributed to the vibration at the top level of the samples during printing, since the samples are considered a cantilever beam. The reason for this is that at higher levels, the samples become more unstable, due to the increase in the deflection of the cantilever at the free end, since the base of the specimens was fixed at the base of the printer bed.

Table 2. Process capability and performance indicators for the triangular pattern.

\begin{tabular}{ccccc}
\hline & Row 1 & Row 2 & Row 3 & Row 4 \\
\hline Mean & a Bottom level & & 20.233 \\
Std. deviation & 20.222 & 20.222 & 20.207 & 0.106 \\
Cp & 0.068 & 0.115 & 0.053 & -0.1 \\
Cpk & 0.98 & 0.58 & 1.25 & 20.247 \\
Cpk & -0.11 & -0.06 & -0.04 & 0.1 \\
Mean & & Middle level & 0.63 \\
Cp & 20.245 & 20.262 & -0.15 \\
\hline Cpk & 0.068 & 0.118 & 0.038 & 1.25 \\
\hline deviation & 0.98 & 0.58 & -0.27 & 20.235 \\
Mean & -0.22 & -0.16 & & 0.103 \\
Cp & & c Top level & 20.255 & 0.64 \\
Cpk & 20.263 & 20.262 & 0.038 & -0.11
\end{tabular}

\subsection{Set 2: Rectilinear Pattern}

Table 3 shows the rectilinear pattern's printed samples, after taking measurements across three different levels and four heights. The table shows the values for the dimensions mean and standard deviations and the Cp and Cpk values. For the bottom level (Table 3a), the dimension's mean changed slightly along the four rows, while the standard deviation decreased from a maximum value of 0.095 in row 1 to a maximum weight of 0.059 in row 3 . The $\mathrm{Cp}$ value increased to a maximum of 1.13 in row 3 , while the minimum was 0.71 (in row 1). Unlike the $C p$, the $C$ pk value was at a maximum in row $1(-0.38)$, while the minimum was in row $3(-0.79)$. For the middle level (Table $3 b)$, there was an apparent fluctuation in the results obtained for the different rows. As for the top-level (Table 3c), the Cpk value is at maximum at row 1 , with a value of -0.50 , and reached its minimum in row 2 , with a value of -0.6 . On the other hand, the $C p$ value was at maximum at row 2 (2.51) and minimum at row 4 (0.35).

\subsection{Set 3: Gyroid Pattern}

Table 4 demonstrates measurement analysis of the gyroid pattern's printed samples across the bottom, middle, and top levels of different rows. For the bottom level of the gyroid printed sample (Table $4 \mathrm{a}$ ), the Cp doubled its value in row 2, compared to row 1, to reach a value of 1.25 , before it declined to a minimum of 0.59 in row 4 . However, Cpk was at minimum in row $3(-1.23)$ and maximum in row $1(-0.82)$. For the middle level (Table $4 b)$, there was a noticeable fluctuation of all parameters. The $\mathrm{Cp}$ value almost doubled to a value of 1.13 in row 2 , then reached its minimum of 0.42 in row 3, before it peaked to a value of 2.05 in row 4 . On the other hand, the maximum value of Cpk was in row $1(-0.32)$ and reached its minimum value of -1.11 in row 2 . As for the top-level (Table $4 \mathrm{c}$ ), the Cp reached its maximum in row 2 (1.74) and declined to a minimum value of 0.7 in row 3 , while the Cpk peaked to -0.73 in row 1 and reached a minimum of -0.92 in row 2 . 
Table 3. Process capability and performance indicators for the rectilinear pattern.

\begin{tabular}{ccccc}
\hline & Row 1 & Row 2 & Row 3 & Row 4 \\
\hline \multicolumn{5}{c}{ Bottom level } \\
\hline Mean & 20.307 & 20.335 & 20.34 & 20.335 \\
Std. deviation & 0.095 & 0.068 & 0.059 & 0.074 \\
Cp & 0.71 & 0.98 & 1.13 & 0.90 \\
Cpk & -0.38 & -0.76 & -0.79 & -0.61 \\
\hline \multicolumn{5}{c}{ b Middle level } \\
Mean & 20.387 & 20.365 & 20.387 \\
Std. deviation & 0.083 & 0.05 & 20.308 & 0.089 \\
Cp & 0.81 & 1.33 & 0.086 & -0.70 \\
Cpk & -0.75 & -1.09 & 0.78 & \\
\hline & & -0.42 & 20.42 \\
Mean & 20.37 & c Top level & 0.192 \\
Std. deviation & 0.115 & 20.402 & 20.392 & 0.35 \\
Cp & 0.58 & 0.027 & 0.109 & -0.57 \\
\hline Cpk & -0.50 & 2.51 & 0.61 & -0.58 \\
\hline
\end{tabular}

Table 4. Process capability and performance indicators for the gyroid pattern.

\begin{tabular}{ccccc}
\hline & Row 1 & Row 2 & Row 3 & Row 4 \\
\hline \multicolumn{5}{c}{ a Bottom level } \\
\hline Mean & 20.468 & 20.393 & 20.333 & 20.59 \\
Std. deviation & 0.109 & 0.053 & 0.1 & 0.112 \\
Cp & 0.61 & 1.25 & 0.66 & 0.59 \\
Cpk & -0.82 & -1.21 & -1.23 & -1.16 \\
\hline \multicolumn{5}{c}{ b Middle level } \\
Mean & 20.313 & 20.397 & 20.458 \\
Std. deviation & 0.118 & 0.059 & 0.432 & 0.033 \\
Cp & 0.56 & 1.13 & 0.42 & -0.90 \\
Cpk & -0.32 & -1.11 & -0.47 & \\
\hline Mean & c Top level & & 20.428 \\
Std. deviation & 20.402 & 20.422 & 20.41 & 0.092 \\
Cp & 0.092 & 0.038 & 0.095 & -0.83 \\
Cpk & 0.73 & 1.74 & 0.7 & -0.74 \\
\hline
\end{tabular}

\subsection{Set 4: Honeycomb Pattern}

Table 5 shows the data of honeycomb's pattern printed samples. For the bottom level (Table 5a), the $\mathrm{Cp}$ increased to a maximum value of 1.19 in row 2 and reached its minimum of 0.28 on row 4 . The Cpk value reached its minimum of -0.7 in row 2 and was at a maximum of -0.26 in row 1 . It can be observed for the middle level (Table $5 b$ ) that the $\mathrm{CP}$ value was at a minimum value of 0.41 in row 1 , then increased in row 2 and reached a maximum of 1.13 in row 3. As for the top-level (Table $5 \mathrm{c}$ ), the Cp peaked to a value of 0.58 in row 2, then dropped to a minimum of 0.12 in row 4 , while the Cpk reached a peak of -0.23 in row 1 and dropped to a minimum of -0.38 in row 4 . 
Table 5. Process capability and performance indicators for the honeycomb pattern.

\begin{tabular}{|c|c|c|c|c|}
\hline & Row 1 & Row 2 & Row 3 & Row 4 \\
\hline \multicolumn{5}{|c|}{ a Bottom level } \\
\hline Mean & 20.338 & 20.318 & 20.293 & 20.443 \\
\hline Std. deviation & 0.18 & 0.056 & 0.059 & 0.236 \\
\hline $\mathrm{Cp}$ & 0.37 & 1.19 & 1.13 & 0.28 \\
\hline Cpk & -0.26 & -0.7 & -0.53 & -0.34 \\
\hline \multicolumn{5}{|c|}{ b Middle level } \\
\hline Mean & 20.288 & 20.305 & 20.273 & 20.362 \\
\hline Std. deviation & 0.163 & 0.109 & 0.059 & 0.092 \\
\hline $\mathrm{Cp}$ & 0.41 & 0.61 & 1.13 & 0.73 \\
\hline Cpk & -0.18 & -0.32 & -0.41 & -0.59 \\
\hline \multicolumn{5}{|c|}{ c Top level } \\
\hline Mean & 20.31 & 20.318 & 20.327 & 20.39 \\
\hline Std. deviation & 0.16 & 0.115 & 0.136 & 0.547 \\
\hline $\mathrm{Cp}$ & 0.42 & 0.58 & 0.49 & 0.12 \\
\hline Cpk & -0.23 & -0.34 & -0.31 & -0.38 \\
\hline
\end{tabular}

\subsection{Set 5: Concentric Pattern}

Table 6 describes the statistical data analysis of concentric pattern after taking measurements of printed samples along three levels and four rows. For the bottom level (Table 6a), the $\mathrm{Cp}$ was at a minimum in row $1(0.94)$, before it reached to a maximum value of 3.22 in row 3 and declined, again, to a value of 1.5 in row 4 . The Cpk was at a maximum of -0.44 in row 1 and reached its minimum of -1.15 in row 3 . In the middle level (Table $6 \mathrm{~b}$ ), the $\mathrm{CP}$ value was at a peak value of 1.13 in rows 1 and 2, before dropping to its minimum of 0.61 in row 3 . The Cpk, on the other hand, was at a maximum of -0.38 in row 1 , before it reached its minimum of -0.73 in row 2 . In the top-level (Table $6 \mathrm{c}$ ), the Cp peaked to a value of 2.05 in row 2 and reached its minimum of 0.68 in row 4 , while the Cpk was at the peak of -0.42 in row 1 , before dropping to its minimum of -0.75 in row 2 .

Table 6. Process capability and performance indicators for the concentric pattern.

\begin{tabular}{ccccc}
\hline & Row $\mathbf{1}$ & Row 2 & Row 3 & Row 4 \\
\hline \multicolumn{4}{c}{ a Bottom level } \\
Mean & 20.293 & 20.342 & 20.348 & 20.352 \\
Std. deviation & 0.071 & 0.08 & 0.021 & 0.044 \\
Cp & 0.94 & 0.84 & 3.22 & 1.5 \\
Cpk & -0.44 & -0.59 & -1.15 & -1.14 \\
\hline \multicolumn{5}{c}{ b Middle level } \\
Mean & 20.267 & 20.33 & 20.377 \\
Std. deviation & 0.059 & 0.059 & 0.109 & 0.065 \\
Cp & 1.13 & 1.13 & 0.61 & 1.03 \\
Cpk & -0.38 & -0.73 & -0.43 & -0.7 \\
\hline & & Top level & \\
\hline Mean & 20.303 & 20.332 & 20.323 & 0.098 \\
Std. deviation & 0.083 & 0.033 & 0.065 & 0.68 \\
Cp & 0.81 & 2.05 & 1.03 & -0.68 \\
\hline
\end{tabular}

Figure 7 illustrates the Cpk values for the five pattern sets at the bottom level of the four rows. It is observed that the highest Cpk value, among the four different rows, is in the triangular pattern and reached a value of -0.04 , while the lowest $(-1.23)$ is in the gyroid pattern. This is in agreement with the findings of Górski et al. [69]. 


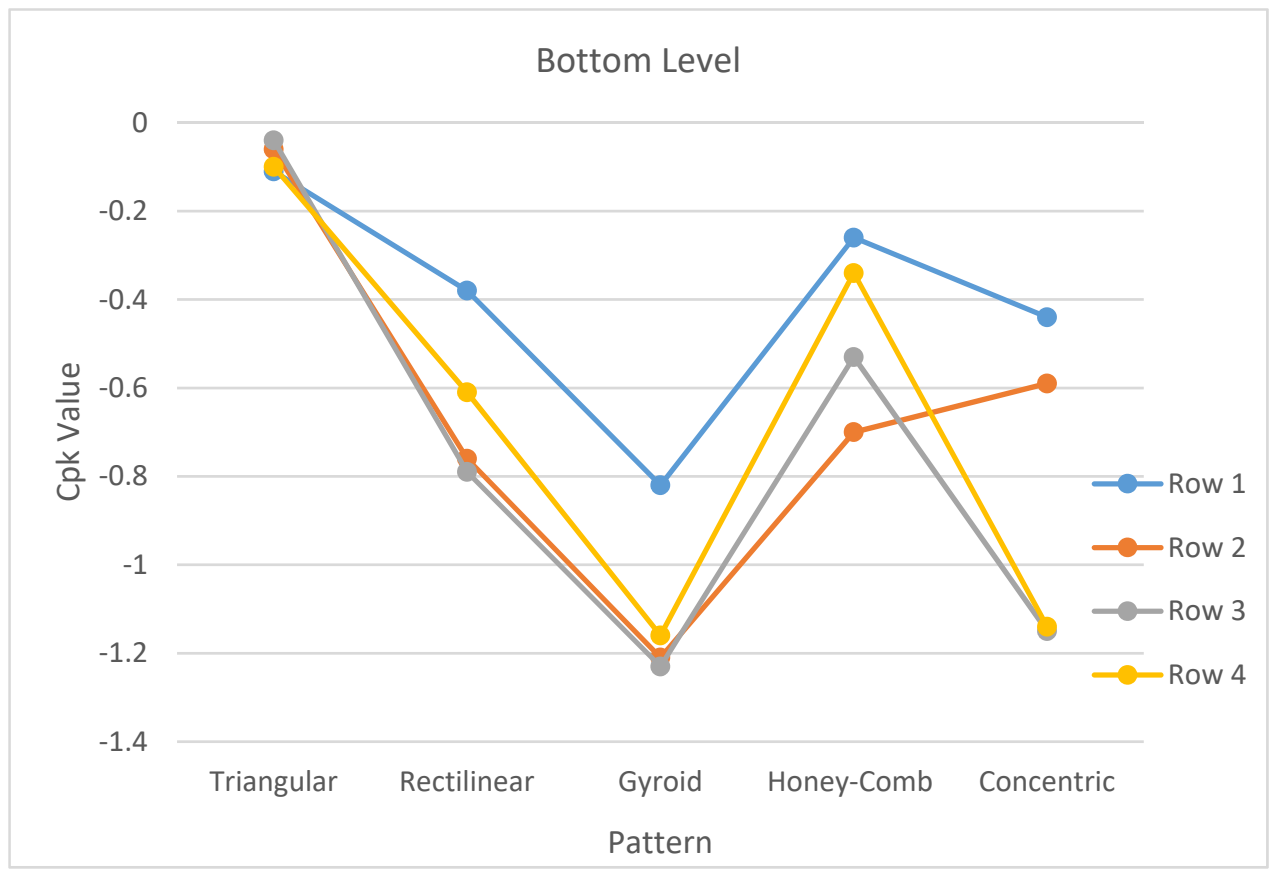

Figure 7. Cpk values for the different patterns and rows at the bottom level.

Figure 8 shows the Cpk values for the five pattern sets at the middle level of the four rows. It was noticed that, among all other patterns, the triangular pattern has the highest Cpk value of -0.15 in row 4 , while the rectilinear design has the lowest Cpk value of -1.09 in row 2.

Figure 9 presents the Cpk values across the top level. As shown in the figure, the minimum Cpk value (-0.92) was obtained in row 2 of the gyroid pattern, while the maximum value $(-0.11)$ was observed in row 4 of the triangular pattern.

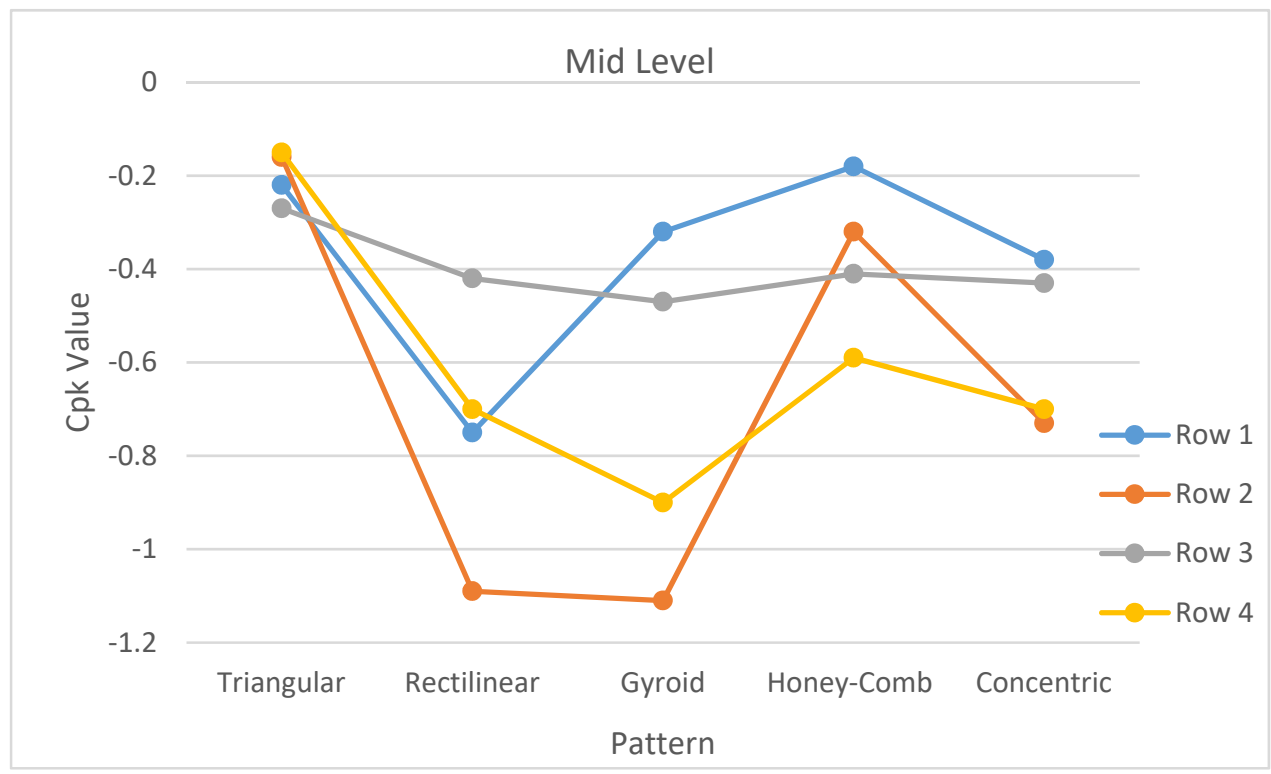

Figure 8. Cpk values for the different patterns and rows at the middle level. 


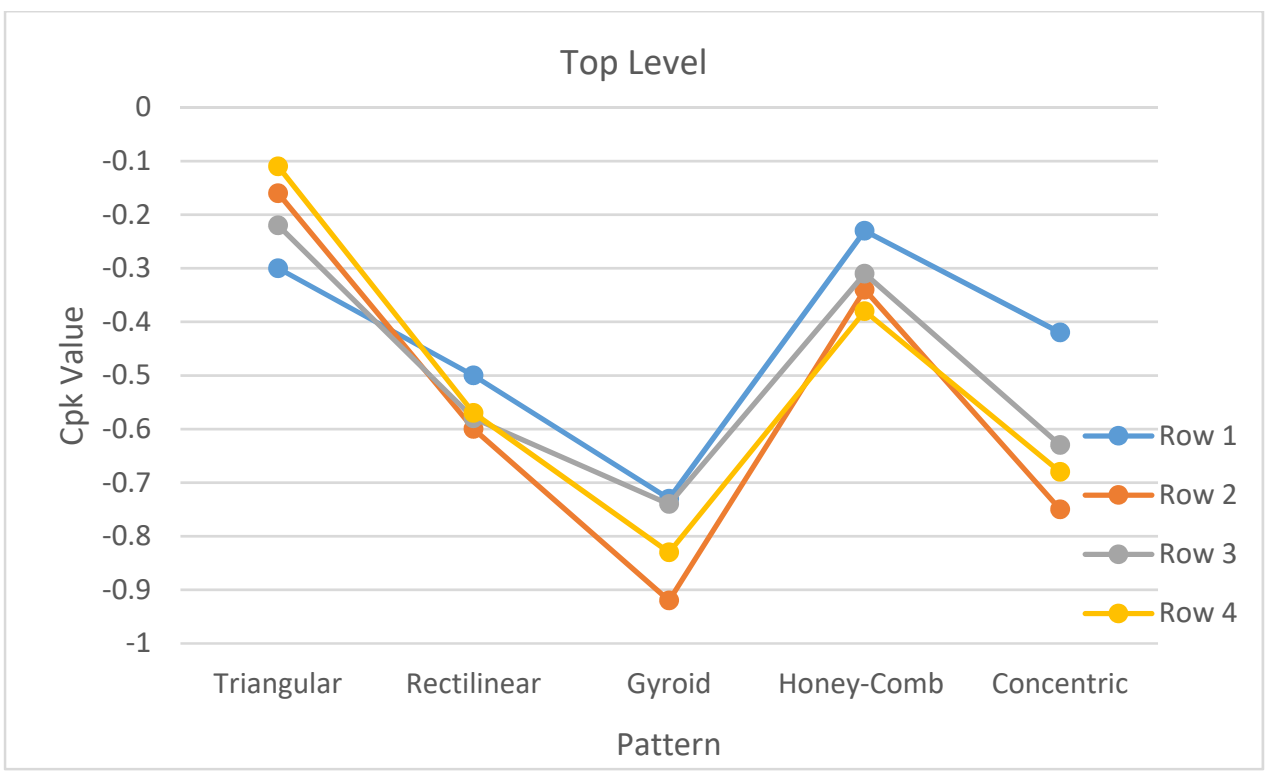

Figure 9. Cpk values for the different patterns and rows at the top level.

The process capability of the printed parts at different levels (bottom, middle, and top) of the five different infill types have also been calculated and summarized in Tables 2-6 and shown in Figures 10-14. Cpk levels below 1 mean that the process is incapable of the requirements, which is shown in the calculations of the 5 different infill types. Each table contains 4 rows, representing a different dimension, along with the Z-axis 20, 40, 80, and $150 \mathrm{~mm}$, respectively [70]. It is shown in five sets that the majority of the curve was outside of the upper and lower specification limits. Looking at the Cpk values of the five different infill patterns in the bottom, middle, and top levels, we find that the values were inconsistent, except for the middle-level honeycomb infill pattern (illustrated in Table 5), where Cpk values decrease with the increase in height.

When comparing the Cpk values, among the different sections of the printed samples, it was noticed that the Cpk values of the triangular infill pattern in set 1 decreased from the bottom to the top of row 1 (Table 2). The same pattern was found in the 2nd set of the rectilinear pattern (Table 3), the 3rd set of the gyroid pattern (Table 4), and the 5th set of the concentric pattern in rows 2, 3, 2, respectively (Table 6). The 5th set also showed an increase in the Cpk values in the 4th row, going from the bottom to the top of the printed samples (Table 6). When analyzing the 4 th set of the honey-comb pattern, an increase in Cpk values in the 3rd row was noticed (Table 5). This is attributed to the movement of the top of the beam, due to the effect of the printing process by the nozzle.

Besides, the nozzle hole diameter of a 3D printer can be varied to obtain the required product quality and reduce manufacturing time. The use of a larger diameter may accelerate the manufacturing time of products but affects the product quality, including the mechanical properties. Therefore, many consequences will be affected, due to the nozzle hole diameter of the 3D printer, including the surface quality, accuracy, and strength of the product [71]. The typical bed temperature, extruder temperature, and printing speed were $60{ }^{\circ} \mathrm{C}, 200{ }^{\circ} \mathrm{C}$, and $80 \mathrm{~mm} / \mathrm{s}$, respectively. In general, the thickness of each layer was considered around $20 \%$ to the nozzle hole diameter. It has been observed that a bigger nozzle hole diameter enhanced the density and tensile strength of the products, though it was not linearly correlated [71]. Analysis of the results showed that the diameter of the nozzle significantly affected the pressure drop along the liquefier, which influences the consistency of the string width, thus affecting the quality of the product's finish. The vital aspect is minimizing the pressure drop to be as low as possible, which will lead to a good quality final product [72]. Besides, the melt pressure in the chamber directly affects the surface morphology and extrusion diameter of the extruded filament. A higher melt 
pressure is beneficial for reducing surface defects of the extruded filament [73], and the strength of the samples decreases with increasing speed [74].

(a) Bottom-Triangular

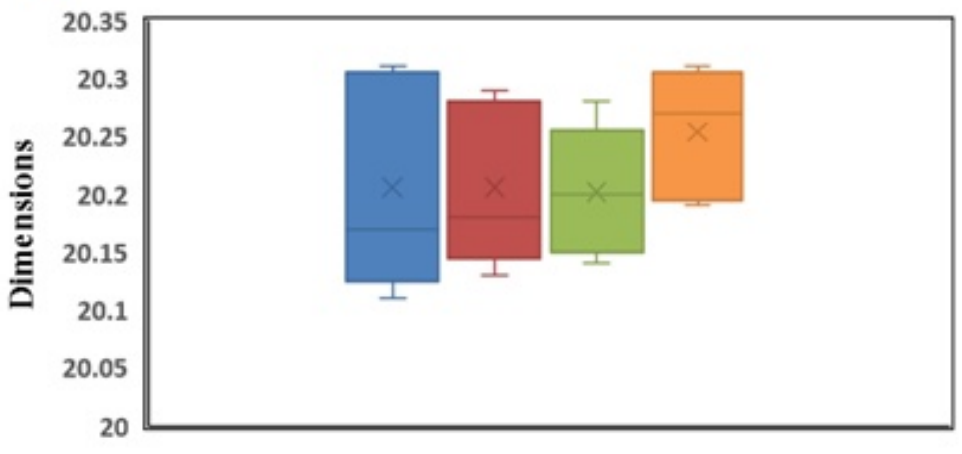

Row $1 \square$ Row $2 \square$ Row $3 \square$ Row 4
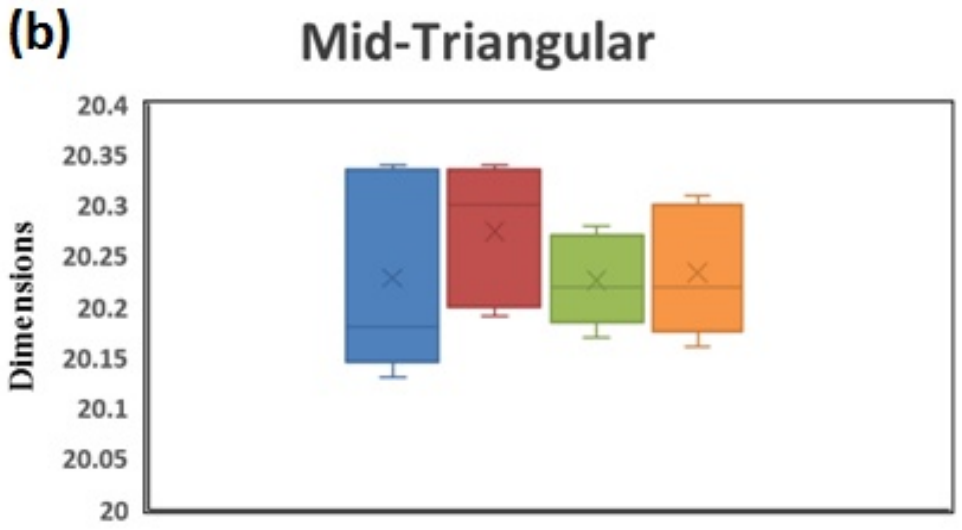

Row1 $\square$ Row2 $\square$ Row3 $\square$ Row4

(c)

Top-Triangular

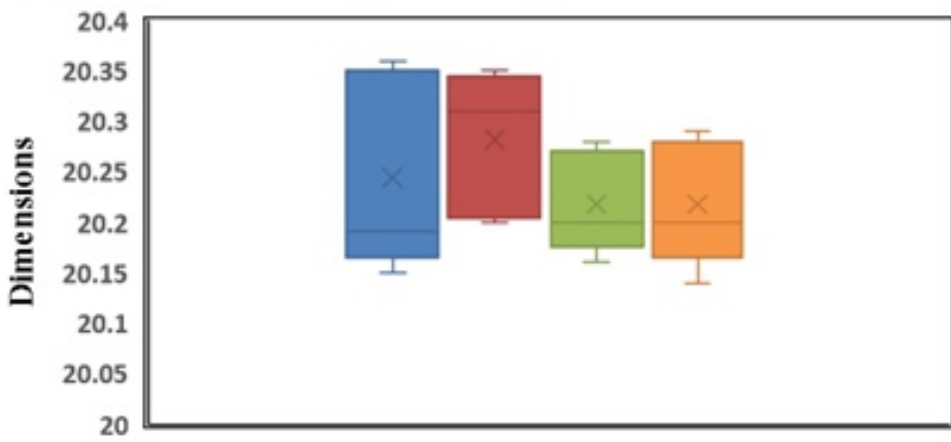

Row1 $\square$ Row2 $\square$ Row3 $\square$ Row4

Figure 10. Box plots and process capability for the four rows of the triangular pattern: (a) bottom level, (b) middle level, (c) top level. 


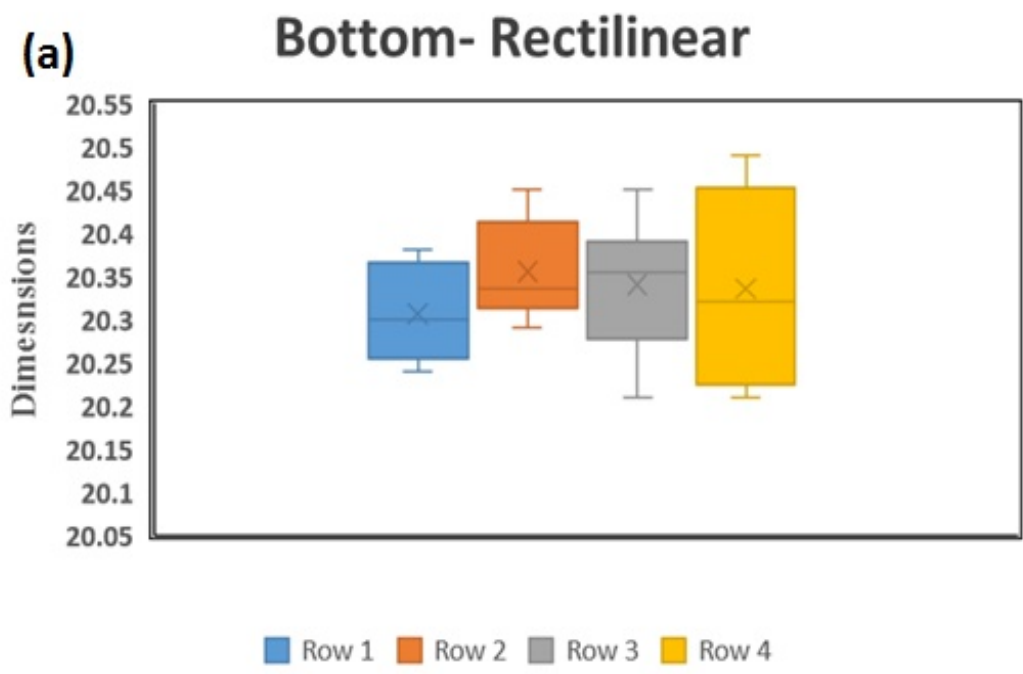

(b)

Mid- Rectilinear

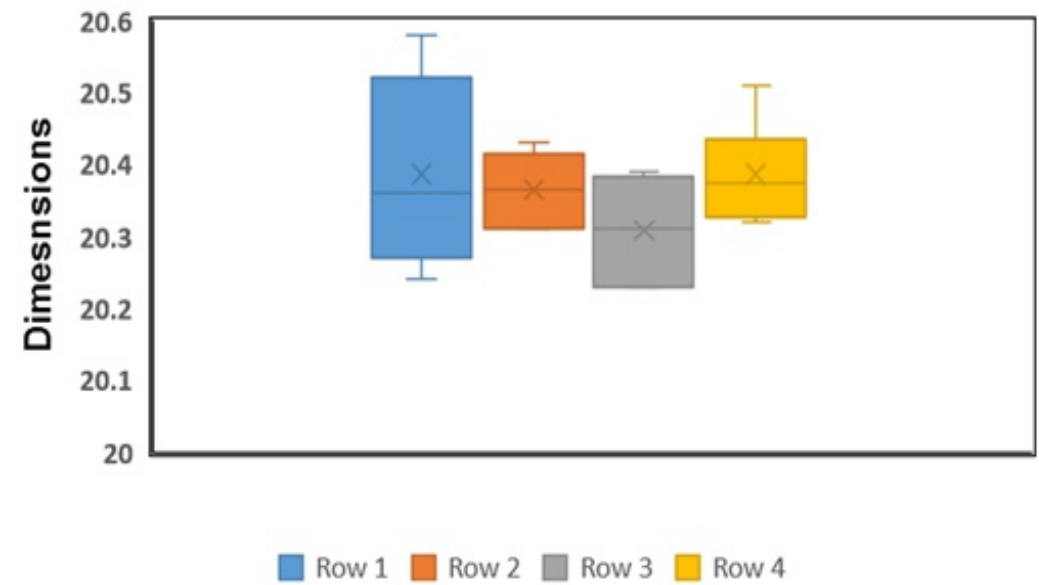

(c) Top- Rectilinear

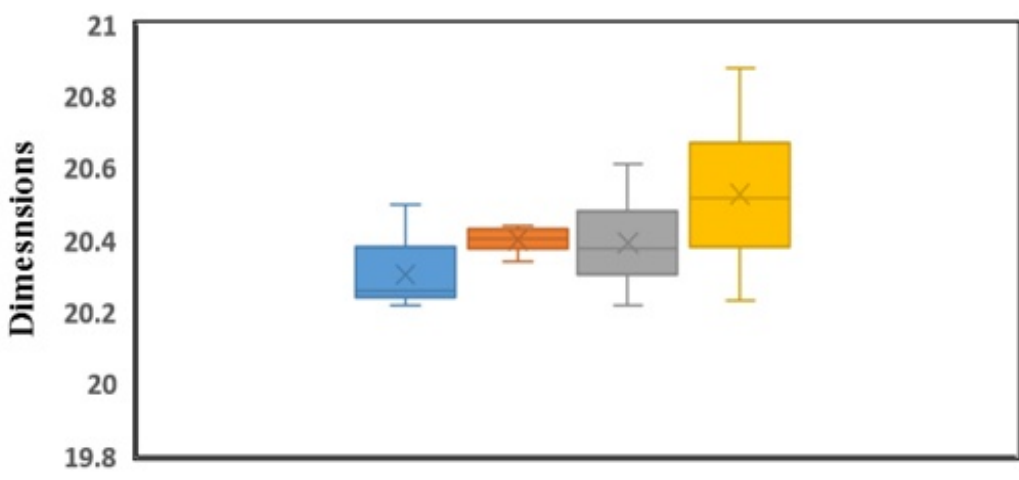

Row $1 \square$ Row $2 \square$ Row $3 \square$ Row 4

Figure 11. Box plots and process capability for the four rows of the rectilinear pattern: (a) bottom level, (b) middle level, (c) top level. 
(a)

Bottom-Gyroid

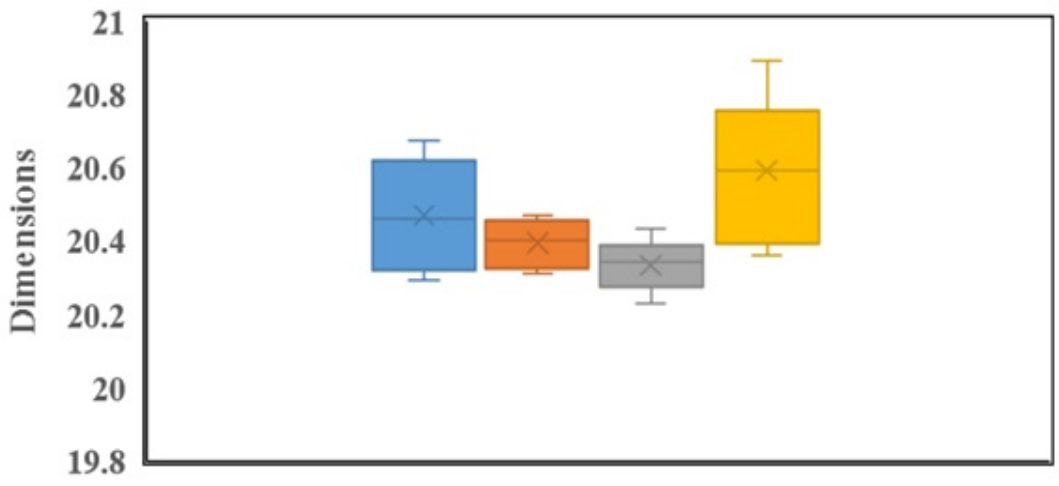

Row $1 \square$ Row $2 \square$ Row $3 \square$ Row 4
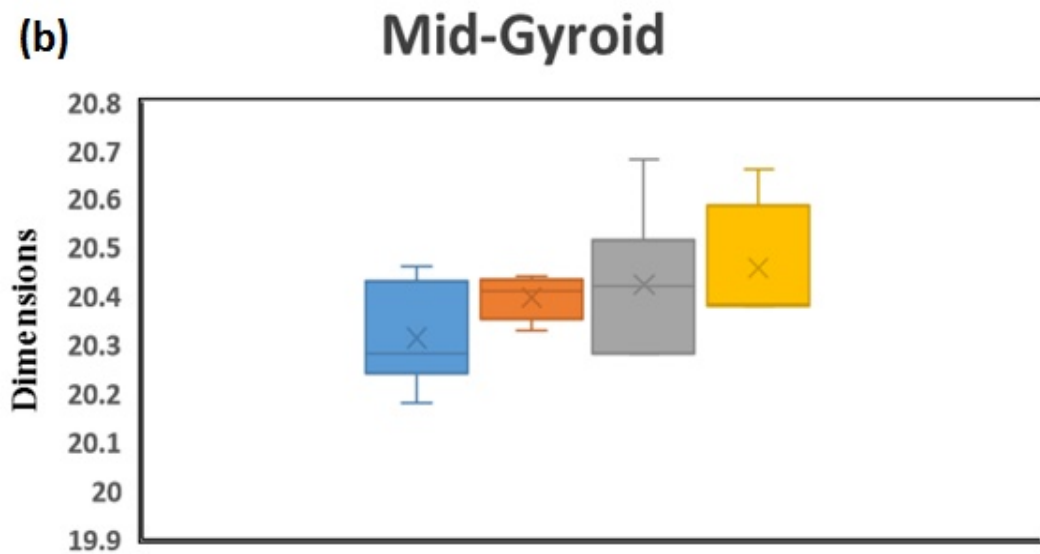

Row $1 \square$ Row $2 \square$ Row $3 \square$ Row 4

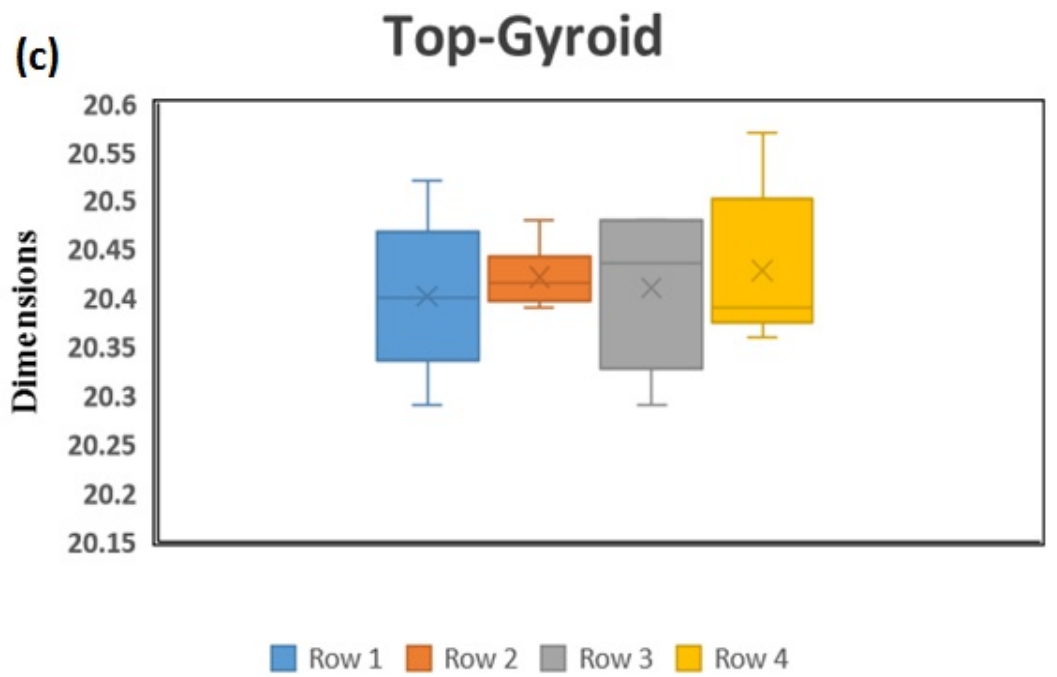

Figure 12. Box plots and process capability for the four rows of the gyroid pattern: (a) bottom level, (b) middle level, (c) top level. 
(a) Bottom- HoneyComb

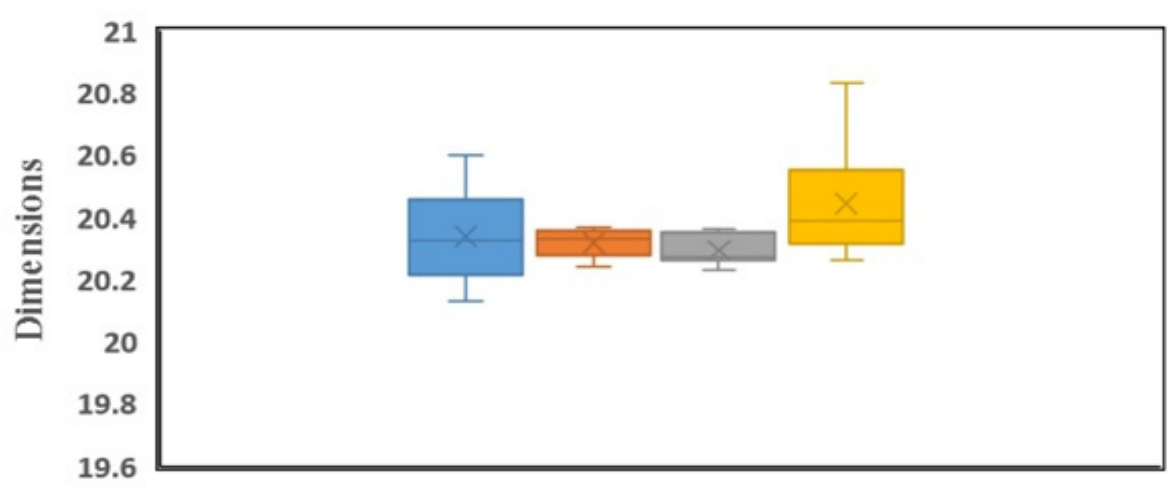

Row $1 \square$ Row $2 \square$ Row $3 \square$ Row 4

(b)

Mid-HoneyComb

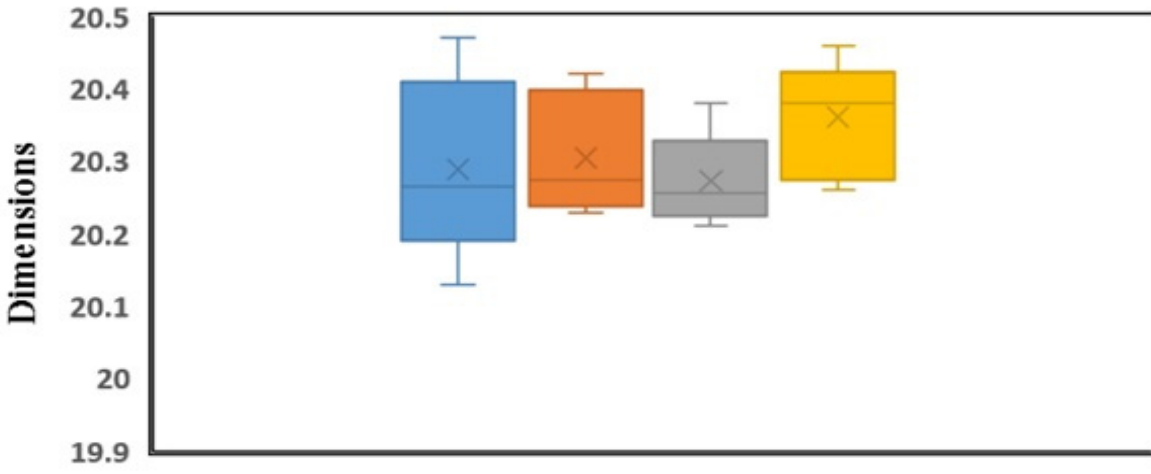

Row $1 \square$ Row $2 \square$ Row $3 \square$ Row 4

(c)

Top-HoneyComb

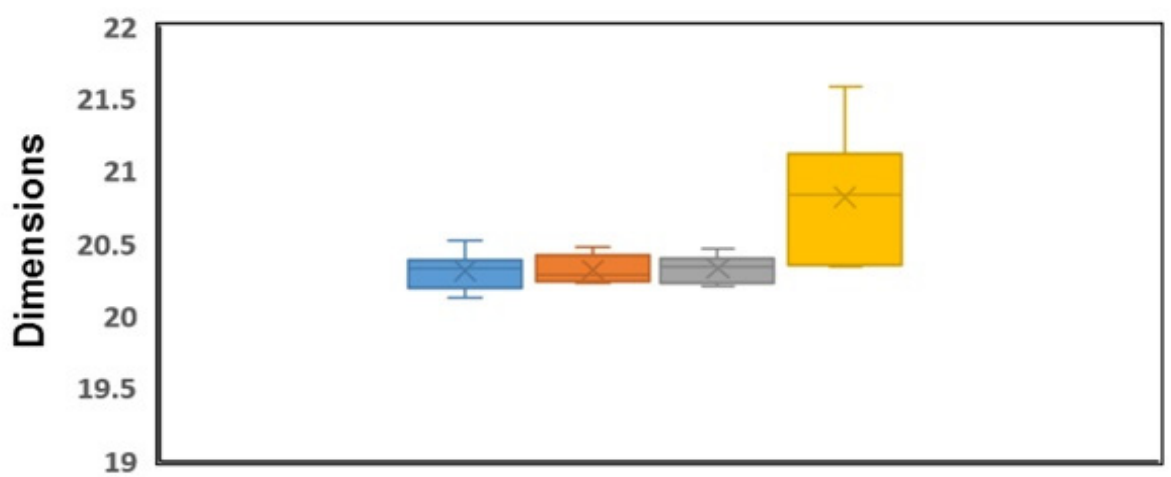

Row $1 \square$ Row $2 \square$ Row $3 \square$ Row 4

Figure 13. Box plots and process capability for the four rows of the honeycomb pattern: (a) bottom level, (b) middle level, (c) top level. 
(a) Bottom-Concentric

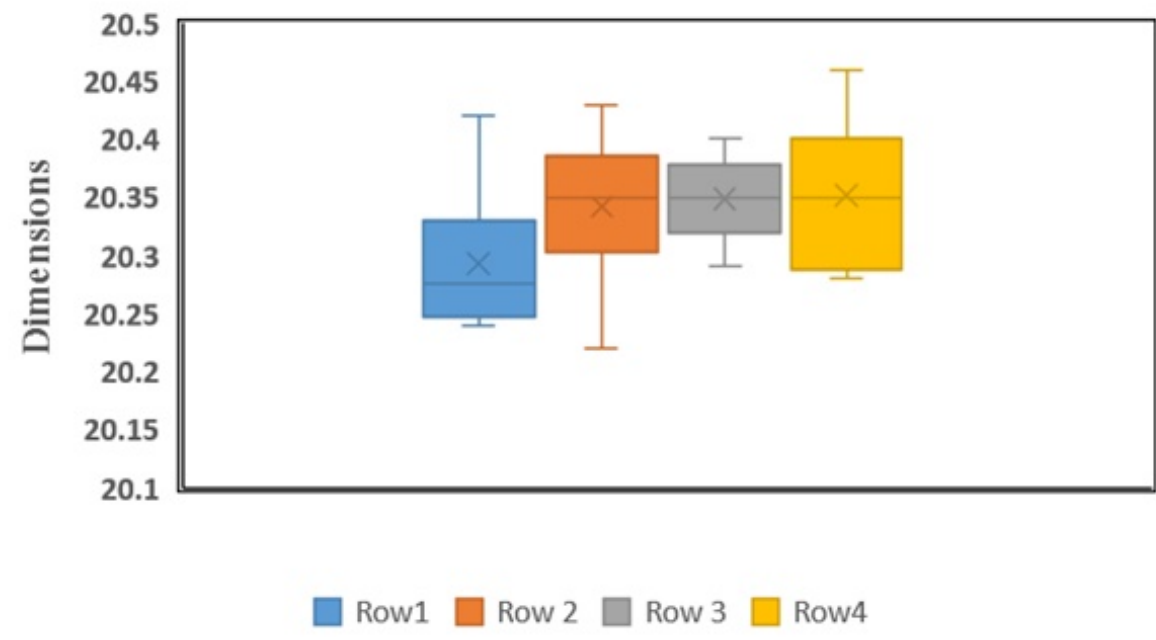

(b)

Mid- Concentric

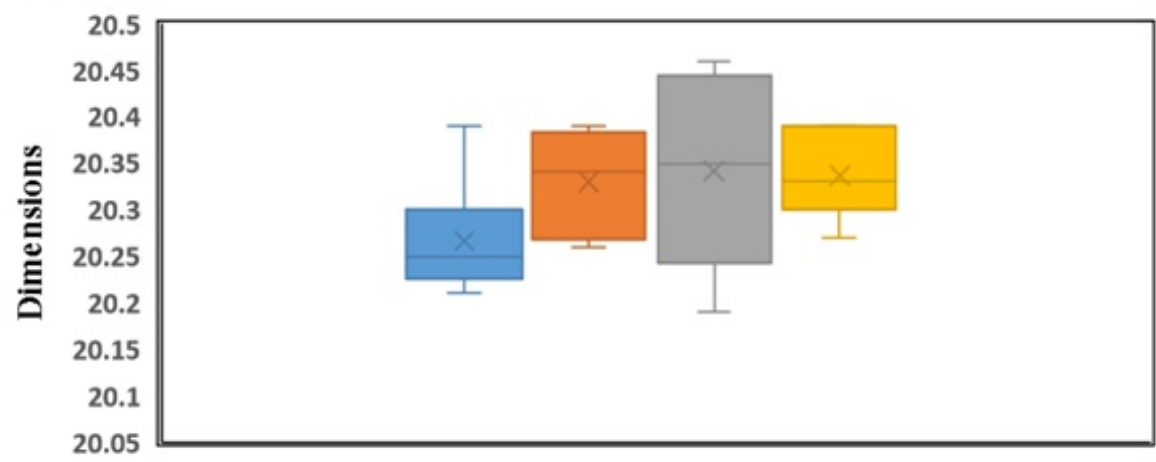

Row1 $\square$ Row $2 \square$ Row $3 \square$ Row4

(c)

Top-Concentric

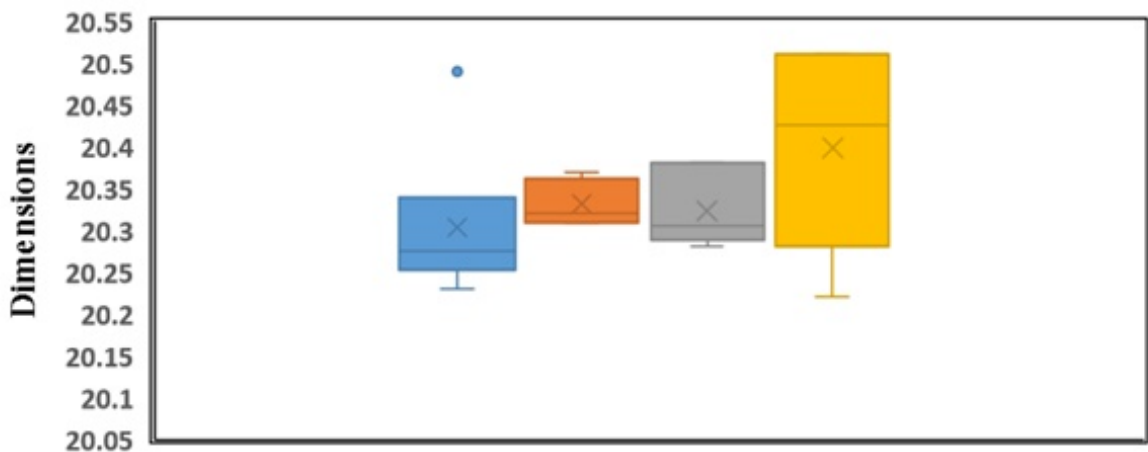

Row1 Row $2 \square$ Row $3 \square$ Row4

Figure 14. Box plots and process capability for the four rows of the concentric pattern: (a) bottom level, (b) middle level, (c) top level. 


\section{Discussion of Results}

The most likely process, capable of meeting the requirement, was investigated in this study to check the highest Cpk values along the bottom, middle, and top sections of the printed samples of the different infill pattern types. The results revealed that the highest Cpk values at the bottom level, among all rows, are at set 1 (triangular pattern), which is in agreement with the findings of $[75,76]$. It has also been observed that the honeycomb dominates the increase of the process capability, whereas the other patterns suffered from a considerable drop in the $\mathrm{Cpk}$, which is attributed to the fact that the honeycomb pattern is of one of the most stable shapes in nature, since this honeycomb structure has attractive properties, such as ample space area, good structural stability, high mechanical strength, low density, buffering humidity fluctuations, and thermal and acoustic insulation [77]. Besides, the hexagonal honeycomb is widely known and intensively studied, owing to its space-filling capacity and structural stability [78]. On the other hand, enhancing the dimensional accuracy of 3D printed products is related to many 3D printer parameters and the geometry of 3D printed components. The efficiency of 3D printers increases when the layer thicknesses are growing, and printing efficiency is high when the layer thickness is high. However, the printed product's quality or dimensional accuracy is deficient, compared with those printed with small layer thicknesses [79]. Moreover, the dimensional precision is affected by a variety of factors, many of which are within the user's control. In contrast, insight was provided into specific trends in printer performance [80]. Besides, the influence of infill design, printer selection, and part orientation will be reflected on the mechanical properties, production, and cost of parts (fabricated using material extrusion additive manufacturing systems) [81].

Looking at the different rows, across all the sets in the mid and top levels, it was found that the highest $\mathrm{Cpk}$ values were obtained by the fourth set (honeycomb pattern), which was expected at this height, caused by the transverse force applied by the nozzle while printing, since the parts are considered a cantilever beam with end applied load, as shown in Figure 6, while the first set (triangular pattern) achieved the highest Cpk values in rows 2, 3, and 4 . For the various infill structures investigated in the study, the apparent disparity in the capabilities of the 3D printing process parts is a reality. Furthermore, it is highly recommended that, when designing $3 \mathrm{D}$ printed products, the $3 \mathrm{D}$ printer's process capability should be considered, in terms of the structure of the 3D printed samples to prevent all issues with the product $[69,82]$.

In general, the assumed Cpk values were used for the standard deviations needed to establish the specification limits, whenever the existing specification is developed. One of the critical elements in creating a new specification is the establishment of appropriate specification limits for the various quality characteristics that are part of the acceptance dimensions [83]. Process capabilities could be performed, concerning the defined tolerance limits, and the results must be analyzed based on the requirements from the statistical process control [84]. Generally, if $\mathrm{Cp}=\mathrm{Cpk}$, the process is centered at the midpoint of the specifications, and when $\mathrm{Cpk}<\mathrm{Cp}$, the process is off-center. The magnitude of $\mathrm{Cpk}$, relative to $\mathrm{Cp}$, directly measures how off-center the process is operating [85]. The use of capability indices is just one of the critical techniques, where Cpk is probably the most commonly used, as it presents the overall process capability index. Most of the Cpk values deal with specific technical abuses. However, the concept is sometimes over-applied to attributes; it is primarily effective for variable data [86]. Moreover, the dimensional accuracy represents the degree of agreement between the manufactured dimension and its designed specification. It is the most critical aspect for ensuring dimensional repeatability of manufactured parts [87]. According to the dimensioning and tolerancing standards [88,89], the dimensional accuracy of a piece is evaluated through its size (size tolerance), and shape (geometric tolerance, including form, orientation, and location).

It has been found that 3D printing can reduce a significant number of labors, which can solve the labor shortage problem [90]. Also, selecting the appropriate material is an essential factor to reduce the $3 \mathrm{D}$ printing cost, especially using biodegradable material, such as 
FLAM (fungal-like adhesive material), where the price is in the range of commodity plastics and 10 times lower than the cost of common filaments for 3D printing, such as PLA and ABS, making it not only more sustainable but also more cost-effective [91]. However, it is clear that the dimensional stability of the 3D printed objects is affected by the elevation of the printed parts that are attributed to the height-to-width ratio, which could be higher than two and approaching the maximum investigated height more than eight times, which will cause dimensional variation, due to the instability condition of the 3D printed objects. Shape stability of the printed part is defined as the stability of the printed layers against settlement and deformation caused by the printing of the subsequent layers [12]. It is observed that the worst dimensional accuracy for specimens with elevated standard deviation error bars was observed, due to tilted layers positioning when models are constructed, as the influence of gravity increases distortion [92]. It is also observed that the height dimension of the FDM test pieces displayed the worst shape error, which reached almost a maximum percentage [93]. Besides, 3D printing technology (especially the fused deposition modeling) subjects the material to rapid heating and cooling; therefore, some degree of undesirable warpage occurs post-fabrication. Thus, four process parameters (the infill shape, infill density, number of perimeters created per layer, and layer height) attribute to the total dimensional error of a representative 3D printed part [94]. Although changing the 3D printing layer thickness does not affect the product's repeatability or surface roughness, changes to the layer thickness and storage time influence the dimensional stability of 3D printed parts [95].

In essence, the influence of 3D printing process parameters on the dimensional accuracy of specimens manufactured using different polymeric materials is attributed to many factors, especially when dealing with recycled material. The nominal values are considered to determine the accuracy percentage for each specimen, in order to estimate the ability of commercial 3D printers [96]. The 3D printed parts accuracy is not very high using commercial, low-cost printers, considering the usual types of equipment used for pieces with no special requirements. Hence, it is of technological interest to have information concerning the accuracy achievable by $3 \mathrm{D}$ printing processes. From a practical point of view, differences could appear between the desired part dimensions and the actual part dimensions. These differences could be generated by the behavior of the melted material, as it gradually advanced through the nozzle and deposited, layer by layer, on the 3D printing equipment plate.

\section{Potential Applications in Construction}

Building materials contribute to around $50 \%$ of the total cost of projects in the construction industry $[97,98]$. Undoubtedly, this high percentage contributes to the escalating costs of construction project. Contractors, therefore, should find other means and alternatives for materials that are durable, reliable, and more cost effective, in order to survive in the current competitive market and cope with the tight budgets of owners. Three-dimensional (3D) printing technologies are transforming the design and manufacture of components and products across many disciplines, but their application in the construction industry is still limited. Material deposition processes can achieve infinite geometries. They have advanced from rapid prototyping and model-scale markets to applications in the fabrication of functional products, large objects, and the construction of full-scale buildings [99]. Studying the durability of materials and structures, including 3D printed structures, is now a critical step in better meeting sustainable development challenges and integrating technical and economic aspects from the design phase into the execution phase [100]. In general, the current study on material printability focused on a yield stress-based mixture design approach or numerical approach for 3D printable mortars, in order to evaluate the performance of the material of different printing trials [101]. The construction industry has embraced digitization and industrialization, in response to the need to increase productivity, optimize material consumption, and improve workmanship. Additive manufacturing $(\mathrm{AM})$, more widely known as $3 \mathrm{D}$ printing, has driven substantial progress in these respects 
in other industries. A number of national and international projects have helped introduce the technique to the construction industry [102]. It has been investigated that some of the components printed, such as walls, are oriented with single or double filaments with interior voids, even can integrate reinforcements and openings, where the geometry of the 3D printed constructions varies between the orthogonal layouts that replicate existing buildings and spherical shapes that reflect printing capabilities [103].

In fact, 3D printed objects made by FDM can be used in several construction applications, as an alternative for masonry wall blocks, bricks, hourdi hollow blocks for slabs, interlock tiles, partition walls, and fillers. To be able to decide whether the 3D printed parts made from the plastic waste produced by FDM printers can be used as a construction material, it is necessary to conduct some measurements and tests and compare the results with those of some materials currently used in the construction of building projects, specially customized multi-layered sandwich panels [104]. There are some concerns regarding the failure of the FDM 3D printed parts [105], but it is promising, especially for customized underground infrastructures [106]. The masses of all specimens were first measured by Mettler PE1600 analytical balance, and the density of each specimen was then calculated using the measured mass and the volume of the specimens. The average density was found to be $368 \mathrm{~kg} / \mathrm{m}^{3}$, with a standard deviation $(\sigma)$ of $14.5 \mathrm{~kg} / \mathrm{m}^{3}$. Compression tests were also performed for the five specimens. It was noticed that specimens with concentric infill patterns sustained a higher maximum applied load, with an average value of $5.058 \mathrm{KN}$. For the five printed FDM samples, the average compressive strength was calculated to be 11.24 MPa. As shown in Table 7, concentric pattern FDM had the highest average compressive strength value of $12.67 \mathrm{MPa}$ and a standard deviation $(\sigma)$ of $0.987 \mathrm{MPa}$. However, the gyroid pattern FDM has the lowest average compressive strength value of $9.63 \mathrm{MPa}$ and a standard deviation $(\sigma)$ of 0.15 . The calculated density and compressive strength values for the five printed patterns are listed in Table 7.

For comparison purposes, some selected non-structural (non-load bearing) elements used in the traditional construction of building projects have been used in this study and compared with the five three-dimensional printed FDM samples. As a matter of fact, the main purpose in this study was to investigate the possibility of using these 3D printed FDM elements as an alternative to traditional non-load bearing construction elements, if it is found feasible. Since 3D printing technology is now booming and becoming a contemporary issue in the country and worldwide, this study suggests the use of 3D printing to produce construction elements from waste plastics and compare it with the traditional elements used for building construction, in terms of their mechanical properties and cost. Several research efforts have used a similar approach to investigate the feasibility of 3D printed elements, as compared to traditional ones. Ortega et al., 2020 [102], for example, investigated the use of 3D printed concrete construction objects and discussed whether the performance of the materials produced using 3D printing could be superior to traditional ones. When conducting this comparison, the authors relied on the data obtained from the industry for these traditional non-load bearing construction elements. Other efforts, along this line, can be found in [107-110].

The selected traditional construction elements include lightweight concrete hollow blocks, ultra-lightweight concrete hollow blocks, lightweight hourdi hollow blocks, lightweight concrete bricks, interlock cement tiles, and regular gypsum board drywalls. Since these selected, non-structural elements are traditionally produced by many manufacturers in the country, the mechanical properties of such elements with the same physical dimensions are almost the same. The average density and compressive strength values for these selected traditional construction elements, as received from the vendors, are shown in Table 7. Table 7 also shows the costs of the 3D printed objects, as well as the costs of the selected traditional construction elements suggested in this study. These costs are shown in United Arab Emirates Dirham (AED) per square meter for each of these elements, where one US\$ equals 3.68 AED. The dimensions associated with the different types of the selected traditional elements are as follows: 
- $\quad$ Type A: $20 \mathrm{~mm} \times 20 \mathrm{~mm} \times 40 \mathrm{~mm}$;

- $\quad$ B: $190 \mathrm{~mm} \times 190 \mathrm{~mm} \times 390 \mathrm{~mm}$;

- $\quad$ C: $200 \mathrm{~mm} \times 200 \mathrm{~mm} \times 400 \mathrm{~mm}$;

- D: $200 \mathrm{~mm} \times 200 \mathrm{~mm} \times 410 \mathrm{~mm}$;

- $\quad$ E: $100 \mathrm{~mm} \times 200 \mathrm{~mm} \times 400 \mathrm{~mm}$;

- $\quad$ F: $80 \mathrm{~mm} \times 100 \mathrm{~mm} \times 200 \mathrm{~mm}$;

- $\quad$ F: $60 \mathrm{~mm} \times 100 \mathrm{~mm} \times 200 \mathrm{~mm}$;

- $\quad$ H: $9.5 \mathrm{~mm}$ thick;

- $\quad$ I: $12.5 \mathrm{~mm}$ thick;

- J: $15 \mathrm{~mm}$ thick.

Table 7. Densities, peak stresses, and prices of the different elements considered in this study.

\begin{tabular}{|c|c|c|c|c|}
\hline Element & Type & $\begin{array}{l}\text { Density } \\
\left(\mathrm{kg} / \mathrm{m}^{3}\right)\end{array}$ & $\begin{array}{c}\text { Compressive } \\
\text { Strength (MPa) }\end{array}$ & $\begin{array}{c}\text { Cost } \\
\left(\mathrm{AED} / \mathrm{m}^{2}\right)\end{array}$ \\
\hline Triangular plastic waste & A & 375 & 11.30 & 75 \\
\hline Rectilinea plastic waste & A & 370 & 10.13 & 74.09 \\
\hline Gyroid pattern plastic waste & A & 344 & 9.63 & 68.75 \\
\hline Honeycomb pattern plastic waste & A & 377 & 12.47 & 75.38 \\
\hline Concentric pattern plastic waste & A & 375 & 12.67 & 75 \\
\hline $\mathrm{LW} *$ concrete $\mathrm{H}^{* *}$ blocks & $\mathrm{B}$ & 923 & 8.40 & 76.25 \\
\hline $\mathrm{ULW}+$ concrete $\mathrm{H}^{* *}$ blocks & $\mathrm{C}$ & 656 & 3.50 & 81.25 \\
\hline $\mathrm{LW}^{*}$ hourdi $\mathrm{H}^{* *}$ blocks & $\mathrm{D}$ & 702 & 3.20 & 70 \\
\hline LW * concrete face bricks & $\mathrm{E}$ & 1100 & 5.00 & 125 \\
\hline \multirow{2}{*}{ Interlock cement tiles } & $\mathrm{F}$ & 2400 & 25.00 & 27 \\
\hline & G & 2400 & 20.00 & 25 \\
\hline \multirow{3}{*}{$\begin{array}{l}\text { Regular GB ++ drywall used for } \\
\text { interior non-load bearing walls }\end{array}$} & $\mathrm{H}$ & 716 & 2.40 & 6.33 \\
\hline & $\mathrm{I}$ & 784 & 2.75 & 8.14 \\
\hline & $\mathrm{J}$ & 800 & 3.00 & 12.22 \\
\hline
\end{tabular}

* LW: lightweight, ${ }^{* *}$ H: hollow, + ULW: ultra-lightweight, ++ GB: gypsum board.

In this study, the cost per square meter of producing the 3D printed objects made from plastic waste (considering the dimensions of these objects) includes the cost of the 3D printer itself (initial investment cost), direct cost of materials, cost of power consumption, direct labor cost, and overheads costs. The cost of these items are the standards costs that includes all cost components for any manufacturing process, including all 3D printed materials [111]. The densities, compressive strengths, and costs for the traditional construction elements considered in this study and listed in Table 7 were obtained from several local vendors. These local vendors provided similar data for the same component with some small differences and the average values of the density, compressive strength, and cost were considered and listed in Table 7. Examples of these local vendors are Ducon Industries [112], Emcon [113], Phoenix Concrete Products [114], Bucomac Block Factory [115], and Emirates Blocks Factory [116]. The cost per square meter used in this study provides an initial cost indication for the purpose of comparison only, while the cost of erecting these elements onsite is not considered in this study.

It was noticed that using 3D objects made from plastic waste using FDM is less costly than traditional lightweight concrete hollow blocks and ultra-lightweight concrete hollow blocks and has higher compressive strengths. Also, printed 3D with gyroid pattern plastic waste has less cost per square meter, as compared with that of lightweight hourdi hollow blocks with a much higher compressive strength. Although the cost per square meter of other patterns of 3D printed objects are slightly higher than those of the lightweight hourdi hollow blocks, this extra cost is offset with their much higher values of compressive strength. It is also noticed that the cost per square meter of 3D printed objects was around $41 \%$ less than that of the traditional lightweight concrete bricks, with a higher compressive strength (more than twice). It is worth mentioning that, although the 3D printed objects used in this study are much more expensive than traditional gypsum board drywall, 
project managers may consider them, since they have much higher compressive strength. However, it is not feasible to use $3 \mathrm{D}$ printed objects using plastic waste as an alternative for interlock cement tiles, since they are more expensive and have less compressive strength.

Despite the limited applications of 3D printed objects in the construction industry, the experimental results of this study explored new horizons in using polymeric waste material, in general, to shape construction elements using 3D printing. As a case study, waste was used to produce 3D construction objects; however, any other plastic waste can be used. Also, the experimental test results can be applied to other industries, as well. For a more comprehensive and precise comparison, the authors suggest conducting further studies in the future to investigate the acoustics properties, fire resistance, durability, heat insulation, water absorption, thermal properties, and labor productivity related to 3D printed elements using plastic waste, as compared to the traditional construction elements considered in this study and other traditional construction components. As a future extension to the present study, the authors are currently consulting other experts in areas related to acoustics, fire resistance, and thermal properties of 3D printed elements to get their feedback and help in conducting such studies and provide their recommendations in this regard. Since the infill pattern of the 3D printed objects will affect the acoustic and thermal properties of these objects, the infill pattern and compressive strengths of $3 \mathrm{D}$ printed objects can be manipulated and customized based on the actual requirements and applications in construction. This customization cannot be achieved by the traditional commercial production of construction elements.

\section{Conclusions}

The 3D printing technology has developed rapidly in recent years [117], due to its significant manufacturing and industrials capabilities, which opened new horizons in different sectors $[118,119]$. However, the technology is no longer as widely used as it used to be, due to certain drawbacks and restrictions, such as the high cost associated with the manufacturing operations. In this study, the process capability of 3D printed samples, with various structures and pattern designs, was considered to reduce unforeseen expenses. It was noticed that Cpk values behaved inconsistently, when comparing the five infill patterns discussed in this study. For example, the Cpk value declined with the Z-axis of the triangular pattern printed sample in the first row only, while it increased in the third row only in the honeycomb pattern. However, it was noticed that the triangular pattern set has the highest Cpk values, as compared with other sets, which means that it has more stability among all other infill structures. In general, the study revealed that for the section of small dimensions with large heights, there is a possibility of having discrepancy in the cross-sectional dimensions of the printed parts due to the deflection of the parts that is reflected in the mean values of the measured dimensions, as well as in the process capability values. This is attributed to the additional vibration that the printed part was subjected to due to its unique design, making the parts subjected to the dynamic excitation of the printer nozzle movement while printing. This could also be a consequence that cannot be avoided in the FDM process, and increasing the printing speed will make the problem even worse. Moreover, it is important to mention that the design must optimize the spaces between the printed samples to the minimum. This is important to reduce the possibility of the long travel of the printing head while moving from one part to another, resulting in the application of an additional force of the printed part.

The study also concluded that 3D printed material from plastic waste is considered a feasible alternative for several traditional construction elements, such as lightweight concrete hollow blocks, ultra-lightweight concrete hollow blocks, and lightweight concrete bricks, since they are less expensive and have higher compressive strength. The cost per square meter of $3 \mathrm{D}$ printed objects is around $41 \%$ less than that of the traditional lightweight concrete bricks with a higher compressive strength. It was also noticed that, although the 3D printed objects used in this study are more expensive than traditional gypsum board drywalls, they may be considered as they have much higher compressive 
strength. It was also observed that using 3D printed object with plastic waste is not feasible as an alternative for interlock cement tiles, since they are more expensive and have less compressive strength. However, it might be considered as an alternative for gypsum board partition walls, since it provides a much higher compressive strength (more than three times).

Author Contributions: Conceptualization, E.Z. and W.A.; methodology, E.Z. and W.A.; software, A.M.; validation, W.A., E.Z., A.M. and A.E.H.; formal analysis, E.Z.; investigation, W.A.; resources, A.E.H. and A.M.; data curation, A.M. and A.E.H.; writing-original draft preparation, W.A., E.Z., A.M. and A.E.H.; writing—review and editing, E.Z. and W.A.; visualization, W.A.; supervision, W.A. and E.Z.; project administration, E.Z.; funding acquisition, E.Z. All authors have read and agreed to the published version of the manuscript.

Funding: This research was funded by the RESEARCH SECTOR of the UNITED ARAB EMIRATES UNIVERSITY, grant number 31N261.

Institutional Review Board Statement: Not applicable.

Informed Consent Statement: Not applicable.

Conflicts of Interest: The authors declare no conflict of interest.

\section{References}

1. ISO/ASTM 52900:2018-06. Additive Manufacturing-Terminology (ISO/ASTM DIS_52900:2018); ISO. 2017. Available online: www.iso.org/standard/69669.html (accessed on 20 September 2021).

2. Ahmed, W.; Siraj, S.; Al-Marzouqi, A.H. Comprehensive characterization of polymeric composites reinforced with silica microparticles using leftover materials of fused filament fabrication 3D printing. Polymers 2021, 13, 2423. [CrossRef]

3. Korotcenkov, G. Metal Oxide Powder Technologies: Fundamentals, Processing Methods and Applications, 1st ed.; Elsevier: Amsterdam, The Netherlands, 2020.

4. Ahmed, W.; Alnajjar, F.; Zaneldin, E.; Al-Marzouqi, A.H.; Gochoo, M.; Khalid, S. Implementing FDM 3D printing strategies using natural fibers to produce biomass composite. Materials 2020, 13, 4065. [CrossRef] [PubMed]

5. Al Darmaki, A.; Al Shamsi, A.; Ahmed, W.K.; Al Jassmi, H. Designing and Developing Innovative Structural Engineering Failure Experiment Using Additive Manufacturing Technology. In Proceedings of the Advances in Science and Engineering Technology International Conferences (ASET), Dubai, United Arab Emirates, 26 March-11 April 2019; pp. 1-6. [CrossRef]

6. Lee, J.Y.; An, J.; Chua, C.K. Fundamentals and applications of 3D Printing for novel materials. Appl. Mater. Today 2017, 7, 120-133. [CrossRef]

7. Chen, Z.; Li, Z.; Li, J.; Liu, C.; Lao, C.; Fu, Y.; Liu, C.; Li, Y.; Wang, P.; He, Y. 3D printing of ceramics: A review. J. Eur. Ceram. Soc. 2019, 39, 661-687. [CrossRef]

8. Bártolo, P. Stereolithography: Materials, Processes and Applications, 1st ed.; Springer: Boston, MA, USA, 2011.

9. Schelly, C.; Anzalone, G.; Wijnen, B.; Pearce, J.M. 3-D printing technologies for education: Bringing additive manufacturing to the classroom. J. Vis. Lang. Comput. 2015, 28, 226-237. [CrossRef]

10. Uzcategui, A.C.; Muralidharan, A.; Ferguson, V.L.; Bryant, S.J.; McLeod, R.R. Understanding and improving mechanical properties in 3D printed parts using a dual-cure acrylate-based resin for etereolithography. Adv. Eng. Mater. 2018, 20, 1800876. [CrossRef]

11. Ciampi, G.; Spanodimitriou, Y.; Scorpio, M.; Rosato, A.; Sibilio, S. Energy performances assessment of extruded and 3D printed polymers integrated into building envelopes for a south Italian case study. Buildings 2021, 11, 141. [CrossRef]

12. Ngo, T.D.; Kashani, A.; Imbalzano, G.; Nguyen, K.T.; Hui, D. Additive manufacturing (3D printing): A review of materials, methods, applications and challenges. Compos. B Eng. 2018, 143, 172-196. [CrossRef]

13. Körner, C. Additive manufacturing of metallic components by selective electron beam melting-A review. Int. Mater. Rev. 2016, 61, 361-377. [CrossRef]

14. Dermeik, B.; Travitzky, N. Laminated object manufacturing of ceramic-based materials. Adv. Eng. Mater. 2020, 22, 2000256. [CrossRef]

15. Fafenrot, S.; Grimmelsmann, N.; Wortmann, M.; Ehrmann, A. Three-dimensional (3D) printing of polymer-metal hybrid materials by fused deposition modeling. Materials 2017, 10, 1199. [CrossRef]

16. Daminabo, S.C.; Goel, S.; Grammatikos, S.A.; Nezhad, H.Y.; Thakur, V.K. Fused deposition modeling-based additive manufacturing (3D printing): Techniques for polymer material systems. Mater. Today Chem. 2020, 16, 100248. [CrossRef]

17. Ning, F.; Cong, W.; Qiu, J.; Wei, J.; Wang, S. Additive manufacturing of carbon fiber reinforced thermoplastic composites using fused deposition modeling. Comp. B Eng. 2015, 80, 369-378. [CrossRef]

18. Yap, C.Y.; Chua, C.K.; Dong, Z.L.; Liu, Z.H.; Zhang, D.Q.; Loh, L.E.; Sing, S.L. Review of selective laser melting: Materials and applications. Appl. Phys. Rev. 2015, 2, 041101. [CrossRef] 
19. Thakar, C.M.; Parkhe, S.S.; Jain, A.; Phasinam, K.; Murugesan, G.; Ventayen, R.J.M. 3D printing: Basic principles and applications. Mater. Today Proc. 2021, 202106. [CrossRef]

20. Kermavnar, T.; Shannon, A.; O'Sullivan, L.W. The application of additive manufacturing/3d printing in ergonomic aspects of product design: A systematic review. Appl. Ergon. 2021, 97, 103528. [CrossRef] [PubMed]

21. Alhamad, I.M.; Ahmed, W.K.; Ali, H.Z.; AlJassmi, H. Chapter 63 D printing applications in mechanical engineering education. In Integrating 3D Printing into Teaching and Learning; Brill: Leiden, The Netherlands, 2019. [CrossRef]

22. Ahmed, W.; Zaneldin, E. The innovation of using 3D printing technology in mechanical and manufacturing engineering. In Proceedings of the IOP Conference Series: Materials Science and Engineering, Los Angeles, CA, USA, 27-29 June 2020; Volume 938. [CrossRef]

23. Araújo, M.R.P.; Sa-Barreto, L.L.; Gratieri, T.; Gelfuso, G.M.; Cunha-Filho, M. The digital pharmacies era: How 3D printing technology using fused deposition modeling can become a reality. Pharmaceutics 2019, 11, 128. [CrossRef]

24. Hagen, A.; Chisling, M.; House, K.; Katz, T.; Abelseth, L.; Fraser, I.; Bradley, S.; Kirsch, R.; Morris, J.; Giles, J.W.; et al. 3D printing for medical applications: Current state of the art and perspectives during the COVID-19 crisis. Surgeries 2021, 2, 25. [CrossRef]

25. Jamali, K.; Kaushal, V.; Najafi, M. Evolution of additive manufacturing in civil infrastructure systems: A ten-year review. Infrastructures 2021, 6, 108. [CrossRef]

26. Sepasgozar, S.M.E.; Shi, A.; Yang, L.; Shirowzhan, S.; Edwards, D.J. Additive manufacturing applications for industry 4.0: A systematic critical review. Buildings 2020, 10, 231. [CrossRef]

27. Cheng, Y.L.; Zhang, L.C.; Chen, F.; Tseng, Y.H. Particle emissions of material-extrusion-type desktop 3D Printing: The effects of infill. Int. J. Precis. Eng. Manuf. Green Technol. 2018, 5, 487-497. [CrossRef]

28. Huang, S.H.; Liu, P.; Mokasdar, A.; Hou, L. Additive manufacturing and its societal impact: A literature review. Int. J. Adv. Manuf. Technol. 2013, 67, 1191-1203. [CrossRef]

29. Kumbhar, N.N.; Mulay, A.V. Post processing methods used to improve surface finish of products which are manufactured by additive manufacturing technologies: A review. J. Inst. Eng. Ser. C 2018, 99, 481-487. [CrossRef]

30. Goh, G.D.; Yap, Y.L.; Tan, H.K.J.; Sing, S.L.; Goh, G.L.; Yeong, W.Y. Process-structure-properties in polymer additive manufacturing via material extrusion: A review. Crit. Rev. Solid State Mater. Sci. 2020, 45, 113-133. [CrossRef]

31. Baich, L.; Manogharan, G.; Marie, H. Study of infill print design on production cost-time of 3D printed ABS parts. Int. J. Rapid Manuf. 2016, 5, 308-319. [CrossRef]

32. Heiny, K. Standard Deviation; Fourth Estate: New York, NY, USA, 2017.

33. Automotive Industry Action Group. Statistical Process Control, Reference Manual, 2nd ed.; Automotive Industry Action Group: Detroit, MI, USA, 2005.

34. International Organization for Standardization. Statistical Methods in Process Management Capability and Performance-Part 2: Process Capability and Performance of Time-Dependent Process Models; ISO 22514-2; ISO: Geneva, Switzerland, 2017.

35. International Organization for Standardization. Geometrical Product Specifications (GPS)_Inspection by Measurement of Workpieces and Measuring Equipment_Part 1: Decision Rules for Verifying Conformity or Nonconformity with Specifications; ISO 14253-1; ISO: Geneva, Switzerland, 2017.

36. Udroiu, R.; Braga, I.C. System performance and process capability in additive manufacturing: Quality control for polymer jetting. Polymers 2020, 12, 1292. [CrossRef]

37. Wu, J.; Wang, C.C.; Zhang, X.; Westermann, R. Self-supporting rhombic infill structures for additive manufacturing. Comput. Aided. Des. 2016, 80, 32-42. [CrossRef]

38. Han, C.P. Effect of testing normality on estimating process capability indices. Qual. Eng. 2006, 18, 391-395. [CrossRef]

39. Somerville, S.E.; Montgomery, D.C. Process capability indeces and non-normal distributions. Qual. Eng. 1996, 9, 305-316. [CrossRef]

40. Mikula, K.; Skrzypczak, D.; Izydorczyk, G.; Warchoł, J.; Moustakas, K.; Chojnacka, K.; Witek-Krowiak, A. 3D printing filament as a second life of waste plastics-A review. Environ. Sci. Pollut. Res. 2021, 28, 12321-12333. [CrossRef] [PubMed]

41. Oussai, A.; Bártfai, Z.; Kátai, L. Development of 3d printing raw materials from plastic waste. a case study on recycled polyethylene terephthalate. Appl. Sci. 2021, 11, 7338. [CrossRef]

42. Singh, R.; Kumar, R.; Singh, P. Reference module in materials science and materials engineering. In Prospect of $3 D$ Printing for Recycling of Plastic Product to Minimize Environmental Pollution; Elsevier Inc.: Amsterdam, The Netherlands, 2015. [CrossRef]

43. Pinho, A.C.; Amaro, A.M.; Piedade, A.P. 3D printing goes greener: Study of the properties of post-consumer recycled polymers for the manufacturing of engineering components. Waste Manag. 2020, 118, 426-434. [CrossRef] [PubMed]

44. Motorcu, A.R.; Güllü, A. Statistical process control in machining, a case study for machine tool capability and process capability. Mater. Des. 2006, 27, 364-372. [CrossRef]

45. Maurya, N.K.; Rastogi, V.; Singh, P. Investigation of dimensional accuracy and international tolerance grades of 3D printed polycarbonate parts. Mater. Today Proc. 2020, 25, 537-543. [CrossRef]

46. Moradi, M.; Meiabadi, S.; Kaplan, A. 3D printed parts with honeycomb internal pattern by fused deposition modelling; experimental characterization and production optimization. Met. Mater. Int. 2019, 25, 1312-1325. [CrossRef]

47. Turhan, D.; Celep, Z.; Zain-Edden, I.K. Transient wave propagation in layered media conducting heat. J. Sound Vib. 1991, 144, 247-261. [CrossRef] 
48. Han, J.; Wu, M.; Ge, Y. A study on the dimension accuracy on the inner structure of the 3D printed parts caused by the scanning strategy. Materials 2019, 12, 1333. [CrossRef]

49. Mohamed, O.A.; Masood, S.H.; Bhowmik, J.L. Experimental investigation of time-dependent mechanical properties of PC-ABS prototypes processed by FDM additive manufacturing process. Mater. Lett. 2017, 193, 58-62. [CrossRef]

50. Dey, A.; Yodo, N. A systematic survey of FDM process parameter optimization and their influence on part characteristics. $J$. Manuf. Mater. Process. 2019, 3, 64. [CrossRef]

51. Mohamed, O.A.; Masood, S.H.; Bhowmik, J.L. Modeling, analysis, and optimization of dimensional accuracy of FDM-fabricated parts using definitive screening design and deep learning feedforward artificial neural network. Adv. Manuf. 2021, 9, 115-129. [CrossRef]

52. Mohamed, O.A.; Masood, S.H.; Bhowmik, J.L. Optimization of fused deposition modeling process parameters: A review of current research and future prospects. Adv. Manuf. 2015, 3, 42-53. [CrossRef]

53. Hajizadeh, K.; Huang, M.; Gibson, I.; Liu, G. Developing a 3D multi-body model of a scoliotic spine during lateral bending for comparison of ribcage flexibility and lumbar joint loading to the normal model. In ASME 2013 International Mechanical Engineering Congress and Exposition; American Society of Mechanical Engineers Digital Collection: New York, NY, USA, 2013.

54. Guevara, R.D.; Vargas, J.A. Process capability analysis plot for a product with bilateral specifications. Rev. Colomb. Estadistica 2011, 34, 287-301.

55. Rusel, B. The Taguchi capability index. J. Qual. Technol. 1991, 23, 17-26.

56. Kotz, S.; Johnson, N.L. Process capability indices-A review, 1992-2000. J. Qual. Technol. 2002, 34, 2-19. [CrossRef]

57. Spiring, F.; Leung, B.; Cheng, S.; Yeung, A. A bibliography of process capability papers. Qual. Reliab. Eng. Int. 2003, 19, 445-460. [CrossRef]

58. Asano, M.; Ikeda, T. Influence of error distribution shape on process capability analysis. In Metrology, Inspection, and Process Control for Microlithography XXIV; International Society for Optics and Photonics: Washington, DC, USA, 2010 ; Volume 7638.

59. Ultimaker, B.V. Stationsplein 32, 3511 ED Utrecht, Netherland. Ultimaker 2 Connect: Start 3D Printing the Ultimaker Way. Ultimaker.com. Available online: https: / ultimaker.com/3d-printers/ultimaker-2-plus-connect (accessed on 15 September 2021).

60. Ultimaker, B.V. Stationsplein 32, 3511 ED Utrecht, Netherland. Ultimaker Cura 4.9: Seamless and Efficient with Digital Library Integration. Ultimaker.com. Available online: https:/ / ultimaker.com/learn/ultimaker-cura-4-9-seamless-and-efficient-withdigital-library-integration (accessed on 15 September 2021).

61. Ultimaker, B.V. Stationsplein 32, 3511 ED Utrecht, Netherland. Ultimaker PLA Material: Highly Versatile, Easy to Print. Ultimaker.com. Available online: https:/ / ultimaker.com/materials/pla (accessed on 15 September 2021).

62. Ahmed, W.; Siraj, S.; Al-Marzouqi, A.H. 3D printing PLA Waste to produce ceramic based particulate reinforced composite using abundant silica-sand: Mechanical properties characterization. Polymers 2020, 12, 2579. [CrossRef]

63. Akbaş, O.E.; Hıra, O.; Hervan, S.Z.; Samankan, S.; Altınkaynak, A. Dimensional accuracy of FDM-printed polymer parts. Rapid Prototyp. J. 2019, 26, 288-298. [CrossRef]

64. Sanchez, F.A.C.; Boudaoud, H.; Hoppe, S.; Camargo, M. Polymer recycling in an open-source additive manufacturing context: Mechanical issues. Addit. Manuf. 2017, 17, 87-105. [CrossRef]

65. Shah, J.; Snider, B.; Clarke, T.; Kozutsky, S.; Lacki, M.; Hosseini, A. Large-scale 3D printers for additive manufacturing: Design considerations and challenges. Int. J. Adv. Manuf. Technol. 2019, 104, 3679-3693. [CrossRef]

66. Lopez Taborda, L.L.; Maury, H.; Pacheco, J. Design for additive manufacturing: A comprehensive review of the tendencies and limitations of methodologies. Rapid Prototyp. J. 2021, 27, 918-966. [CrossRef]

67. Zhu, C.; Li, T.; Mohideen, M.M.; Hu, P.; Gupta, R.; Ramakrishna, S.; Liu, Y. Realization of circular economy of 3D printed plastics: A review. Polymers 2021, 13, 744. [CrossRef]

68. Gil Muñoz, V.; Muneta, L.M.; Carrasco-Gallego, R.; Marquez, J.D.J.; Hidalgo-Carvajal, D. Evaluation of the circularity of recycled PLA filaments for 3D printers. Appl. Sci. 2020, 10, 8967. [CrossRef]

69. Górski, F.; Wichniarek, R.; Kuczko, W.; Zawadzki, P.; Buń, P. Dimentional accuracy of parts manufactured by 3D printing for interactionin virtual reality. Adv. Sci. Technol. Res. J. 2017, 11, 279-285. [CrossRef]

70. Loh, G.H.; Pei, E.; Gonzalez-Gutierrez, J.; Monzón, M. An overview of material extrusion troubleshooting. Appl. Sci. 2020, 10, 4776. [CrossRef]

71. Triyono, J.; Sukanto, H.; Saputra, R.M.; Smaradhana, D.F. The effect of nozzle hole diameter of $3 \mathrm{~d}$ printing on porosity and tensile strength parts using polylactic acid material. Open Eng. 2020, 10, 762-768. [CrossRef]

72. Sukindar, N.A.; Ariffin, M.K.A.; Baharudin, B.T.H.T.; Jaafar, C.N.A.; Ismail, M.I.S. Analyzing the effect of nozzle diameter in fused deposition modeling for extruding polylactic acid using open source 3D printing. J. Teknol. 2016, 78, 7-15. [CrossRef]

73. Geng, P.; Zhao, J.; Wu, W.; Ye, W.; Wang, Y.; Wang, S.; Zhang, S. Effects of extrusion speed and printing speed on the 3d printing stability of extruded peek filament. J. Manuf. Process. 2019, 37, 266-273. [CrossRef]

74. Miazio, Ł. Impact of print speed on strength of samples printed in FDM technology. Agric. Eng. 2019, 23, 33-38. [CrossRef]

75. Siraj, I.; Bharti, P.S. Process capability analysis of a 3D printing process. J. Interdiscip. Math. 2020, 23, 175-189. [CrossRef]

76. Modi, Y.K.; Sahu, K.K. Process capability analysis of binder jetting 3D printing process for fabrication of calcium sulphate based porous bone scaffolds. Aust. J. Mech. Eng. 2020, 1-9. [CrossRef]

77. Heng, L.; Wang, B.; Li, M.; Zhang, Y.; Jiang, L. Advances in fabrication materials of honeycomb structure films by the breath-figure method. Materials 2013, 6, 460-482. [CrossRef] 
78. Basurto-Vázquez, O.; Sánchez-Rodríguez, E.P.; McShane, G.J.; Medina, D.I. Load distribution on PET-G 3D prints of honeycomb cellular structures under compression load. Polymers 2021, 13, 1983. [CrossRef]

79. Herath, H.M.D.B.; Thalagala, S.; Gamage, P. Enhancing the dimensional accuracy of components fabricated using rapid prototyping technique by optimizing machine parameters of a 3D printer. In Proceedings of the 2019 IEEE International Conference on Industrial Engineering and Engineering Management (IEEM), Macao, China, 15-18 December 2019. [CrossRef]

80. Hernandez, D.D. Factors affecting dimensional precision of consumer 3D printing. Int. J. Aviat. Aeronaut. Aerosp. 2015, 2, 2. [CrossRef]

81. Chen, R.; Baich, L.; Lauer, J.; Senesky, D.G.; Manogharan, G. Design for Additive Manufacturing-Effects of Part Orientation, Printer Selection, and Infill Density on Mechanical Properties and Production Cost. engrXiv 2020. [CrossRef]

82. Chval, Z.; Raz, K.; Sedlacek, F. Dimension stability of thin-walled parts from 3d printed composite materials. Struct. Integr. 2019, 5, 91-92. [CrossRef]

83. Burati, J.L. Evaluating specification limits. Transp. Res. Rec. J. Transp. Res. Board 2006, 1946, 92-98. [CrossRef]

84. Budzik, G.; Woźniak, J.; Paszkiewicz, A.; Przeszłowski, Ł.; Dziubek, T.; Dębski, M. Methodology for the Quality Control Process of Additive Manufacturing Products Made of Polymer Materials. Materials 2021, 14, 2202. [CrossRef]

85. Montgomery, D.C. Introduction to Statistical Quality Control, 6th ed.; Wiley: Hoboken, NJ, USA, 2009.

86. Anjard, R.; Hagerty, D.; Griffith, G.; Liu, S.-T.; Mustonen, E.; Pasfield, D. Cpk applications-Uses and abuses. Microelectron. Reliab. 1991, 31, 1123-1125. [CrossRef]

87. Dimitrov, D.; van Wijck, W.; Schreve, K.; De Beer, N.; Meljer, J. An investigation of the capability profile of the three dimensional printing process with an emphasis on the achievable accuracy. CIRP Ann. 2003, 52, 189-192. [CrossRef]

88. Conway, H.G. Engineering Tolerances: A Study of Tolerances, Limits, and Fits for Engineering Purposes, with Full Tables of All Recognized and Published Tolerance Systems; Pitman: London, UK, 1971.

89. Standards Australia International. Technical Drawing; Standards Australia International: Sydney, Australia, 2002.

90. Hossain, A.; Zhumabekova, A.; Paul, S.; Kim, J. A review of 3D printing in construction and its impact on the labor market. Sustainability 2020, 12, 8492. [CrossRef]

91. Sanandiya, N.; Vijay, Y.; Dimopoulou, M.; Dritsas, S.; Fernandez, J.G. Large-scale additive manufacturing with bioinspired cellulosic materials. Sci. Rep. 2018, 8, 1-8. [CrossRef]

92. Hriţuc, A.; Slătineanu, L.; Mihalache, A.; Dodun, O.; Coteaţă, M.; Nagîț, G. Accuracy of polylactide parts made by 3d printing. Macromolecular Symposia. Macromol. Symp. 2020, 1, 1900064. [CrossRef]

93. Alsoufi, M.S.; Elsayed, A.E. Surface roughness quality and dimensional accuracy-A comprehensive analysis of $100 \%$ infill printed parts fabricated by a personal/desktop cost-effective FDM 3D printer. Mater. Sci. Appl. 2018, 9, 11-40. [CrossRef]

94. Azhikannickal, E.; Uhrin, A. Dimentional stability of 3D printed parts: Effects of process parameters. Ohio J. Sci. 2019, 119, 9-16. [CrossRef]

95. Sabbah, A.; Romanos, G.; Delgado-Ruiz, R. Impact of layer thickness and storage time on the properties of 3d-printed dental dies. Materials 2021, 14, 509. [CrossRef]

96. Hanon, M.M.; Zsidai, L.; Ma, Q. Accuracy investigation of 3D printed PLA with various process parameters and different colors. Mater. Today Proc. 2021, 42, 3089-3096. [CrossRef]

97. Alabi, B.; Fapohunda, J. Effects of increase in the cost of building materials on the delivery of affordable housing in South Africa. Sustainability 2021, 13, 1772. [CrossRef]

98. Caldas, C.H.; Menches, C.L.; Reyes, P.M.; Navarro, L.; Vargas, D.M. Materials management practices in the construction industry. Pract. Period. Struct. Des. Constr. 2015, 20, 04014039. [CrossRef]

99. Thmasebinia, F.; Niemelä, M.; Ebrahimzadeh Sepasgozar, S.M.; Lai, T.Y.; Su, W.; Reddy, K.R.; Shirowzhan, S.; Sepasgozar, S.; Marroquin, F.A. Three-dimensional printing using recycled high-density polyethylene: Technological challenges and future directions for construction. Buildings 2018, 8, 165. [CrossRef]

100. Lafhaj, Z.; Dakhli, Z. Performance indicators of printed construction materials: A durability-based approach. Buildings 2019, 9, 97. [CrossRef]

101. Lafhaj, Z.; Rabenantoandro, A.Z.; El Moussaoui, S.; Dakhli, Z.; Youssef, N. Experimental approach for printability assessment: Toward a practical decision-making framework of printability for cementitious materials. Buildings 2019, 9, 245. [CrossRef]

102. Ortega, G.S.; Madrid, J.A.; Olsson, N.O.E.; Ríos, J.A.T. The application of 3D-printing techniques in the manufacturing of cementbased construction products and experiences based on the assessment of such products. Buildings 2020, 10, 144. [CrossRef]

103. García-Alvarado, R.; Moroni-Orellana, G.; Banda-Pérez, P. Architectural evaluation of 3D-printed buildings. Buildings 2021, 11, 254. [CrossRef]

104. Ahmed, W.; Ahmed, S.; Alnajjar, F.; Zaneldin, E. Mechanical performance of three-dimensional printed sandwich composite with a high-flexible core. Proc. Inst. Mech. Eng. Part L J. Mater. Des. Appl. 2021, 235, 1382-1400. [CrossRef]

105. Ahmed, W.; Zaneldin, E.; Kabbani, S. Fracture mechanics performance of through-thickness crack of polymeric 3D printed components. Lecture Notes in Mechanical Engineering. In Proceedings of the 8th International Conference on Fracture, Fatigue and Wear, Ghent, Belgium, 26-27 August 2020; Wahab, M.A., Ed.; Springer: Singapore. Available online: https://doi-org.uaeu.idm.oclc. org/10.1007/978-981-15-9893-7_19 (accessed on 15 September 2021).

106. Zaneldin, E.; Al Khatib, O.; Ahmed, W. Investigating the use of no-dig technologies for underground utilities in developing countries. Innov. Infrastruct. Solut. 2020, 5, 17. [CrossRef] 
107. Gibbons, G.J.; Williams, R.; Purnell, P.; Farahi, E. 3d printing of cement composites. Adv. Appl. Ceram. 2010, 5, 287-290. [CrossRef]

108. Zahabizadeh, B.; Segundo, I.R.; Pereira, J.; Freitas, E.; Camões, A.; Tavares, C.J.; Teixeira, V.; Cunha, V.M.C.F.; Costa, M.F.M.; Carneiro, J.O. Development of photocatalytic 3D-printed cementitious mortars: Influence of the curing, spraying time gaps and $\mathrm{TiO}_{2}$ coating rates. Buildings 2021, 11, 381. [CrossRef]

109. Ji, G.; Ding, T.; Xiao, J.; Du, S.; Li, J.; Duan, Z. A 3d printed ready-mixed concrete power distribution substation: Materials and construction technology. Materials 2019, 9, 1540. [CrossRef]

110. Chong, S.; Pan, G.-T.; Khalid, M.; Yang, T.C.-K.; Hung, S.-T.; Huang, C.-M. Physical characterization and pre-assessment of recycled high-density polyethylene as 3d printing material. J. Polym. Environ. 2017, 2, 136-145. [CrossRef]

111. Sullivan, W.G.; Wicks, E.M.; Koelling, C.P. Engineering Economy, 17th ed.; Pearson: New York, NY, USA, 2020.

112. Ducon Industries, National Industries Park, P.O. Box 262394, Dubai, UAE. Available online: https://www.800blocks.ae/ (accessed on 20 September 2021).

113. Emcon, P.O. Box 62942, Dubai, UAE. Available online: https://www.emcongcc.com/our-products/concrete-products / (accessed on 20 September 2021).

114. Phoenix Concree Products, Industrial Area, P.O. Box 50621, Dubai, UAE. Available online: https:/ / www.phoenixdubai.com/ products.html (accessed on 20 September 2021).

115. Bucomac Block Factory, P.O. Box 5021, Sharjah, USE. Available online: http:/ / www.bucomac.com/dubai_factory.html\# (accessed on 20 September 2021).

116. Emirates Blocks Factory, P.O. Box 31901, Abu Dhabi, UAE. Available online: https://www.emiratesblocks.ae/ (accessed on 20 September 2021).

117. Drummer, D.; Cifuentes-Cuéllar, S.; Rietzel, D. Suitability of pla/tcp for fused deposition modeling. Rapid Prototyp. J. 2012, 6, 500-507. [CrossRef]

118. Ahmed, W.K.; Alhamad, I.M. 3D printing innovations in UAE: Case study: Abu Dhabi summer challenge 2017. In Proceedings of the 2018 Advances in Science and Engineering Technology International Conferences (ASET), Dubai, United Arab Emirates, 6 February-5 April 2018. [CrossRef]

119. Mohammad, M.; Masad, E.; Al-Ghamdi, S.G. 3D concrete printing sustainability: A comparative life cycle assessment of four construction method scenarios. Buildings 2020, 10, 245. [CrossRef] 